UCRL-ID-122898

\title{
Geomechanical Analysis of the Large Block Test
}

\author{
S. C. Blair \\ P. A. Berge \\ H. F. Wang
}

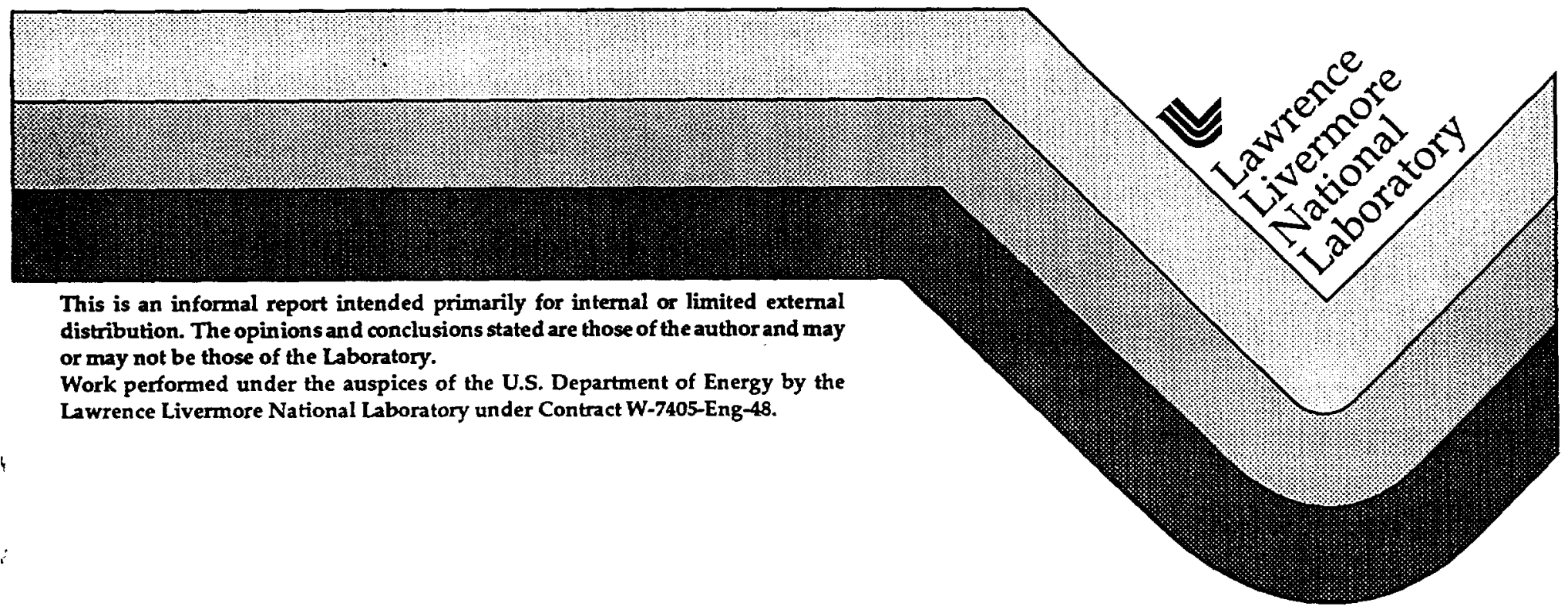




\section{DISCLAIMER}

This document was prepared as an account of work sponsored by an agency of the United States Government. Neither the United States Government nor the University of California nor any of their employees, makes any warranty, express or implied, or assumes any legal liability or responsibility for the accuracy, completeness, or usefulness of any information, apparatus, product, or process disclosed, or represents that its use would not infringe privately owned rights. Reference herein to any specific commercial product, process, or service by trade name, trademark, manufacturer, or otherwise, does not necessarily constitute or imply its endorsement, recommendation, or favoring by the United States Government or the University of California. The views and opinions of authors expressed herein do not necessarily state or reflect those of the United States Government or the University of California, and shall not be used for advertising or product endorsement purposes.

This report has been reproduced directly from the best available copy.

Available to DOE and DOE contractors from the Office of Scientific and Technical Information

P.O. Box 62, Oak Ridge, TN 37831

Prices available from (615) 576-8401, FTS 626-8401

Available to the public from the

National Technical Information Service

U.S. Department of Commerce

5285 Port Royal Rd.,

Springfield, VA 22161 


\section{Geomechanical Analysis of the Large Block Test}

S. C. Blair, P. A. Berge, and H. F. Wang 


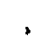

. 


\section{Contents}

Problem Description .......................................................................................................... 1

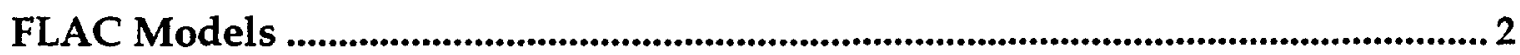

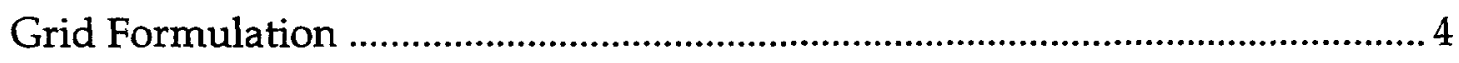

Initial and Boundary Conditions …….................................................................

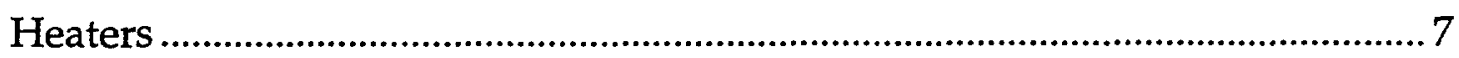

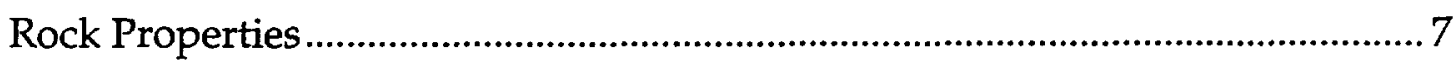

ABAQUS Models .................................................................................................................... 10

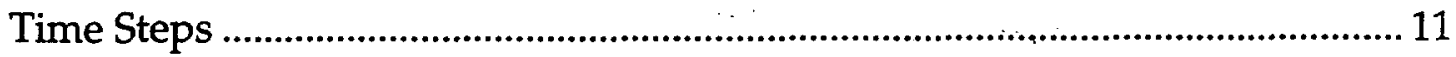

Grids, Nodes, and Elements ................................................................................ 11

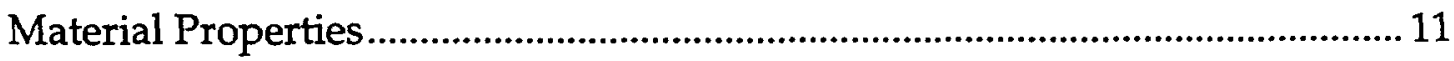

Initial and Boundary Conditions ..................................................................... 11

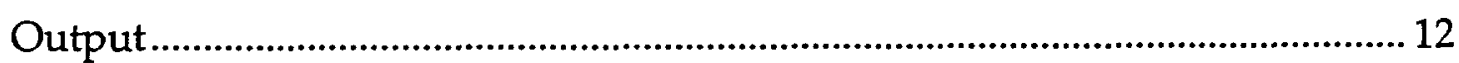

FLAC Modeling Results ................................................................................................ 12

FLAC Thermal Results .................................................................................... 12

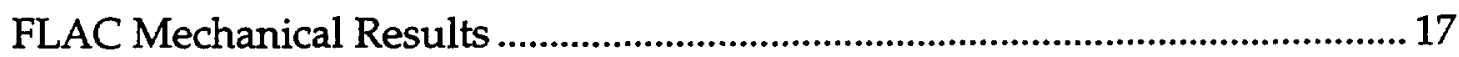

ABAQUS Modeling Results ............................................................................................ 24

Comparison of FLAC and ABAQUS Simulations ...................................................... 32

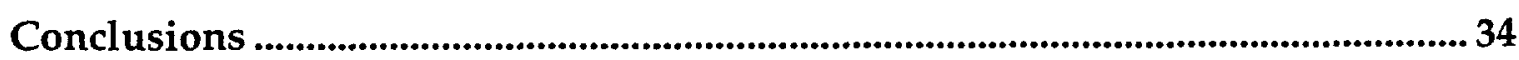

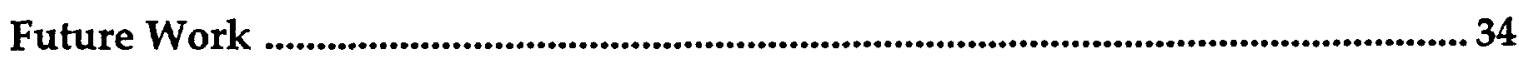

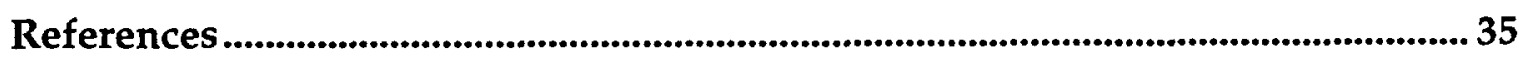

Appendix A: FLAC Mechanical Model Input File ...................................................... 36

Appendix B: FLAC Thermal Model Input File .............................................................39 


\section{Geomechanical Analysis of the Large Block Test}

The Yucca Mountain Site Characterization Project is investigating the Topopah Spring tuff at Yucca Mountain, Nevada, to determine whether it is suitable as a host rock for the disposal of high-level nuclear wastes. The Large Block Test (LBT) at Fran Ridge was planned as part of the project to investigate coupled thermal-mechanical-hydrological and geochemical processes that may occur in the repository near-field environment. This test would be performed on an excavated block of Topopah Spring tuff and would provide information at an intermediate scale ( $1-10 \mathrm{~m}$ ) that would help evaluate existing models for repository performance.

As part of the LBT, we are analyzing the coupled thermal-mechanicalhydrological behavior of the block in response to heating. Our objectives are to aid in the experimental design of the test, to evaluate different thermal and constitutive models, and to evaluate several different numerical methods. In this report, we present results of thermal-mechanical simulations of the heat-up phase of the LBT conducted using two different numerical codes that are commercially available: a two-dimensional (2D), finite-difference model called FLAC and a three-dimensional (3D), finite-element model, called ABAQUS.

The purpose of this initial numerical modeling is to calculate temperatures, stresses, and displacements in two and three dimensions for a simplified representation of the large block. In reality, numerous joints and fractures complicate the behavior of the large block significantly. Nonetheless, these simulations provide a general understanding of the thermal-mechanical behavior to be expected in the LBT.

\section{Problem Description}

The large block at Fran Ridge is $3.0 \mathrm{~m} \times 3.0 \mathrm{~m}$ at the base and $4.5 \mathrm{~m}$ tall. Five heaters would span the width of the block at a height of $1.5 \mathrm{~m}$ above the ground surface. The heaters would eventually raise the block temperature to about $140^{\circ} \mathrm{C}$ in the plane of the heaters, and a thermal gradient would be developed between the heater plane and the top of the block, which would be maintained at a constant temperature of $60^{\circ} \mathrm{C}$. For the test design that our model simulates, the heat flux on the sides of the block would be maintained at zero, and the block would be essentially unconfined, with a maximum horizontal stress of $0.2 \mathrm{MPa}$ (30 psi) imposed on its sides.

In the LBT, the block would be heated for about 75 days, until the temperature at the heater plane would reach about $140^{\circ} \mathrm{C}$. During this period, 
constant power would be supplied to the heaters. Once the heater plane reached $140^{\circ} \mathrm{C}$, the heater power would be reduced until a steady-state condition would be reached in the block. This condition would be expected to occur about 180 days after heating begins. The steady-state condition would then be maintained for the duration of the heating phase.

Figure 1 shows the anticipated heater power and temperature at the heater plane vs time from the start of the test. The FLAC and ABAQUS codes were used to simulate the heat-up phase of the LBT. The numerical models are one-way weakly coupled in the sense that the temperature field produces thermal stresses, but mechanical stresses do not in turn influence temperatures. The temperature field is calculated as a function of time from a thermal diffusion model. In simulations conducted using each code, the sides and top of the block are assumed to be insulated. Also, the ground surface beside the base of the block is assumed to be isothermal. The two codes are similar in that the mechanical model in each uses the temperature field at given times to apply thermal loading.

For these simulations, all of the surface stresses are assumed to be zero. In the 2D (FLAC) analysis, only one-half of the block in cross section is modeled; in the 3D (ABAQUS) case, only one-quarter of the block is modeled. Therefore, the two symmetry planes are given boundary conditions of zero displacement normal to the plane. The bottom of the model lies several meters below the ground surface, and it is also a zero displacement boundary. Up to 75 days, the temperature effects of the heating extend at most $2 \mathrm{~m}$ below and extend less than $1 \mathrm{~m}$ to the sides of the block; therefore, the model boundaries have little effect on the thermomechanical behavior of the large block itself.

\section{FLAC Models}

One numerical method considered is a time-dependent, finite-difference method called a Fast Lagrangian Analysis of Continua (FLAC), capable of treating both mechanical and thermally induced stresses and deformations. It is a 2D code in which materials are represented by arbitrarily shaped, quadrilateral zones, and it can use several built-in constitutive models to describe material behavior.

In this study, we used version 3.22 of the FLAC code. A detailed description of the code can be found in the FLAC User's Manual (Itasca Consulting Group, Inc., 1993). All of the FLAC modeling described in this report assumes a 2D, plane strain geometry. This geometry is equivalent to having infinite thickness in the third dimension, or to being in a symmetry plane (no net strain) in the third dimension. The plane of the 2D FLAC models is the vertical plane perpendicular to the long axis of the heaters for the LBT. The FLAC models all use linear 


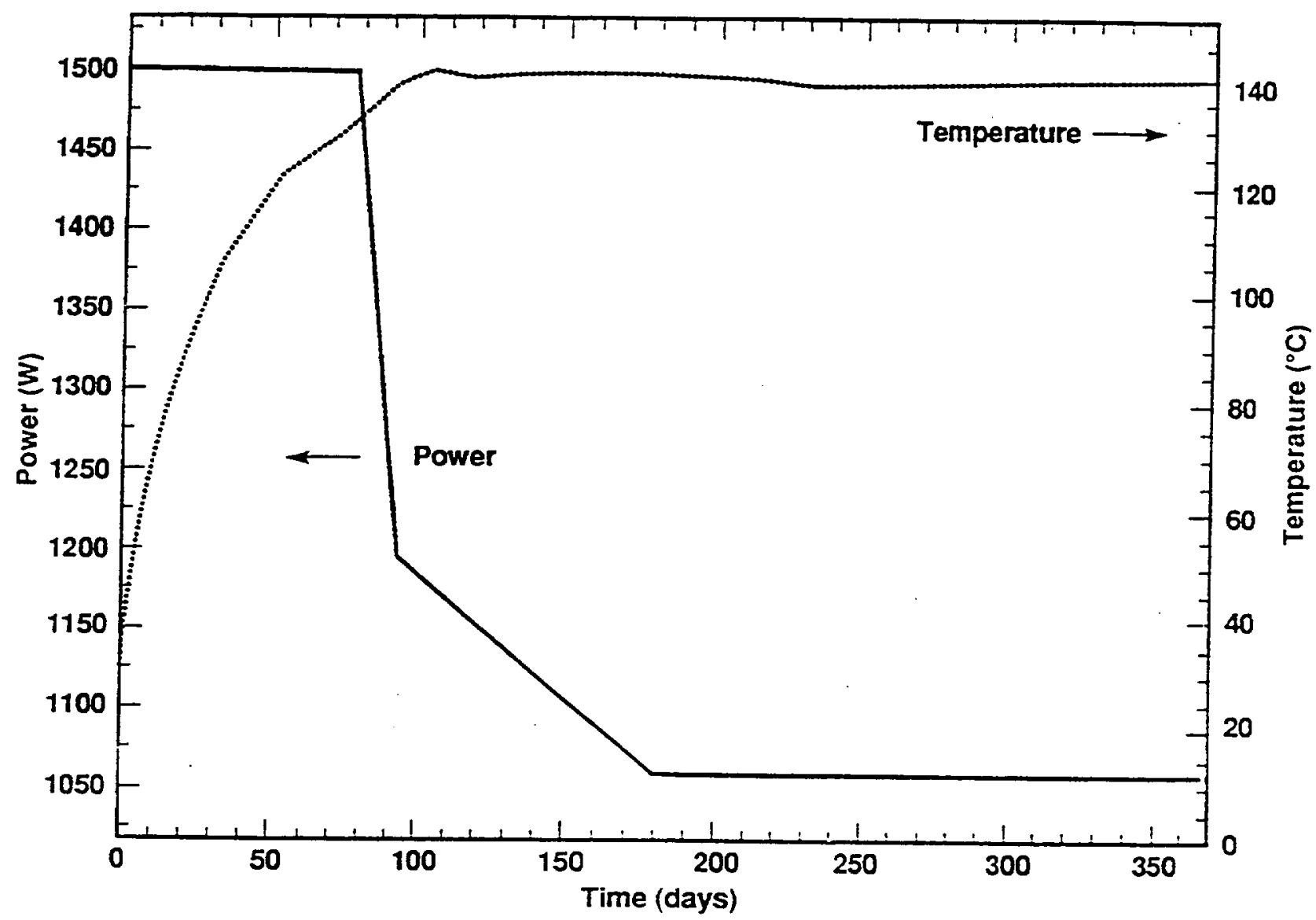

Figure 1. Total heating power and borehole temperature histories predicted for the Large Block Test (after Lee, 1995). 
mechanical and thermal properties where mechanical properties (e.g., elastic moduli) and thermal properties (e.g., thermal expansion coefficient) are independent of stress and temperature. Constitutive relations are either isotropic elastic or make use of the ubiquitous joint model capability of the FLAC code. The thermal response in all models assumes isotropic heat conduction.

The procedure for running a FLAC model to simulate the LBT is first to create a file that provides information about the grid used in the model, the mechanical and thermal properties used to represent the rock, the mechanical boundary conditions, and the initial conditions. Appendix A shows an example of such a file. Next, FLAC is run in the mechanical mode with this file as input, to bring the model to initial mechanical equilibrium. This run usually requires several thousand steps. Mechanical steady state is reached when additional steps do not produce significant additional displacement; e.g., an additional 1000 steps results in less than $1 \mathrm{~mm}$ displacement for a model that showed displacements on the order of $1 \mathrm{~cm}$ for initial steps. The equilibrium state is then saved in a FLAC output file.

Another input file is then created to provide information about the thermal boundary conditions, initial conditions, and heat sources. Appendix B shows an example of such an input file. FLAC is run in the thermal mode with the new input file and the saved file from the previous run, for the number of time steps required to follow the desired heating schedule. The resulting temperature field in the model is saved in a new FLAC output file. Note that the size of a time step is set to be slightly smaller than the area of the smallest grid element divided by the thermal diffusivity of the rock. Thus, heat transfer can be resolved at the scale of the grid, but the model will not require an excessive amount of time for computing the temperature field.

Finally, FLAC is run again in the mechanical mode, to compute the displacements and stresses that result from the thermal loading. The mechanical and thermal modeling in FLAC can be described as a one-way weak coupling, with the mechanical state affected by the temperature field, but with the thermal state independent of the displacements and the stress field.

\section{Grid Formulation}

Several important limitations of FLAC must be considered when developing a grid to represent the LBT configuration. According to the FLAC User's Manual, errors in stress and displacement due to edge effects will be small (below $6 \%$ ) if fixed model boundaries are placed at distances of at least five times the length of the region to be modeled. For a large block that is $4.5 \mathrm{~m}$ high, the model must therefore have distant edges at least $23 \mathrm{~m}$ below and at least $23 \mathrm{~m}$ beyond the 
block. The model must represent the $3 \mathrm{~m} \times 4.5 \mathrm{~m}$ block while retaining enough small-scale detail to properly represent the 5-cm- (2-in.-) diameter heater holes. The result is a grid with more gridlines concentrated in the block region, particularly around the heater holes, and fewer gridlines toward the far edges of the model. According to the FLAC User's Manual, grid elements must have aspect ratios that do not exceed 5:1, and the areas of two adjacent elements should not exceed a 4:1 ratio. The number of elements in the model, $N$, determines how much computer time is required for a steady-state solution, with run time proportional to $N^{3 / 2}$. For example, a 1000-element model may require a few minutes to run on a Sparc10 workstation, and a 4000-element model would take 8 times longer to run on the same computer.

The gridding used in all of the FLAC models described in this report is almost the same as that used by Lee (1995) for hydrothermal modeling. The only differences are that we eliminated one gridline $1 \mathrm{~cm}$ below the top of the large block in Lee's grid to avoid aspect ratio problems, and near the far edges of the model, we moved gridlines slightly to prevent areas of adjacent elements from exceeding the 4:1 ratio. In our grid, there are 26 vertical and 37 horizontal gridlines, for a total of 900 elements.

In the FLAC models, the large block is represented as a set of zones $4.5 \mathrm{~m}$ high and having a $1.5 \mathrm{~m}$ width for half of the block. (Only half of the large block is modeled, since the block is symmetrical for a vertical cross section.) Grid elements within the block have sizes varying from $5 \mathrm{~cm}$ by $5 \mathrm{~cm}$ to $10 \mathrm{~cm}$ by $20 \mathrm{~cm}$. Below the block, the element sizes increase to a maximum of $16 \mathrm{~m}$ by $16 \mathrm{~m}$ at the far edges of the model, but are smaller than $1 \mathrm{~m}$ by $1.5 \mathrm{~m}$ within a few meters of the large block. The heaters in the block are represented as $10 \mathrm{~cm}$ by $10 \mathrm{~cm}$ elements, placed $3 \mathrm{~m}$ below the top of the block. These heater elements are larger than the actual heater holes, but the heater power was scaled accordingly (as described later in this section). Figure 2 shows a detail of the grid for the large block models, and exact positions of all gridlines can be found in the FLAC input file in Appendix A.

\section{Initial and Boundary Conditions}

Initial conditions used in the FLAC modeling set all initial stresses to zero within all grid elements, and set temperatures initially to $20^{\circ} \mathrm{C}$ in all elements. The gravitational acceleration is $9.8 \mathrm{~m} / \mathrm{s}^{2}$. A set of boundary conditions was used for the FLAC modeling, as follows: The axis of symmetry at the left edge of the model, for the center of the large block, was modeled as an adiabatic boundary fixed in the horizontal direction. The top of the block was also adiabatic and had an applied compressive stress of $0.1 \mathrm{MPa}$ (nominally zero) to simulate atmospheric pressure. 


FLAC (Version 3.22)

Figure 2. Grid and heater locations for LBT simulations using FLAC. 
The right edge of the block was adiabatic, and it had an applied compressive stress of $0.1 \mathrm{MPa}$. The horizontal boundary representing the ground surface was an isothermal boundary set to a temperature of $20^{\circ} \mathrm{C}$ with an applied compressive stress of $0.1 \mathrm{MPa}$. The far right edge and bottom edge of the model were fixed in both the horizontal and vertical directions and were isothermal boundaries fixed at $20^{\circ} \mathrm{C}$. These conditions simulate the unconfined LBT with guard heaters to prevent heat flow from the sides of the block. Modeling of the top boundary of the block could be improved by allowing heat flux out until the top reaches a temperature of $60^{\circ} \mathrm{C}$ and then converting to an isothermal condition. This is a nontrivial problem in FLAC that will be addressed in future modeling. The present simple adiabatic condition allows the top of the block to reach $60^{\circ} \mathrm{C}$ too soon, but it avoids the problem of heat flux downward from the top, that would occur if the top boundary were initially set at an isothermal condition at $60^{\circ} \mathrm{C}$ (e.g., Lee, 1995).

\section{Heaters}

All of the FLAC modeling described in this report represented the heat sources as $300-W$ heaters placed at $60-\mathrm{cm}$ intervals at a level $3 \mathrm{~m}$ below the top of the large block (Figure 2). This configuration follows that used by Lee (1995). Lee's heating schedule began with about 75 days of heating at a constant power of $1500 \mathrm{~W}$ with five heaters, followed by reducing the power to $1200 \mathrm{~W}$ and finally achieving a steady state at about $1050 \mathrm{~W}$ at an elapsed time of about 180 days. The FLAC modeling follows the first 75 days of Lee's heating schedule, using a constant power of $1500 \mathrm{~W}$.

Each heater is represented in the model as an internal heat source, specified in units of watts per square meter of grid element per meter in the third (infinite) direction. The actual heater holes in the LBT will each have a radius of $2.5 \mathrm{~cm}$ and a length of $2.7 \mathrm{~m}$, i.e., a cross-sectional area of $0.0020 \mathrm{~m}^{2}$ and a volume of 0.0053 $\mathrm{m}^{3}$. The ratio of power to volume for the heaters is then about $57000 \mathrm{~W} / \mathrm{m}^{3}$ for a $300-W$ heater. For a $10-\mathrm{cm}$ by $10-\mathrm{cm}$ grid element having an area of $0.010 \mathrm{~m}^{2}$, this $300-\mathrm{W}$ heater is represented by scaling $57000 \mathrm{~W} / \mathrm{m}^{3}$ by the ratio of the heater hole cross-sectional area to the grid element area, to obtain a source of 11000 $\mathrm{W} / \mathrm{m}^{3}$ throughout the grid element. This is clearly an appropriate procedure for representing the LBT heaters in the FLAC modeling because, as results described in later sections show, temperature fields agree with the temperature field produced by Lee (1995) for modeling the LBT.

\section{Rock Properties}

Table 1 lists input parameters for physical properties used in the FLAC modeling. We used the simplest thermal conduction model available in the 
FLAC code. This isotropic heat conduction modeling required three input parameters: thermal conductivity, specific heat, and the thermal expansion coefficient. FLAC requires that a bulk modulus, a shear modulus, and a density be specified for any mechanical model. This is the complete set of mechanical properties in the elastic case. The ubiquitous joint model is an anisotropic plasticity model that assumes a series of weak planes embedded in a MohrCoulomb solid. It requires eight additional parameters to specify where and how yield may occur. These parameters and the ubiquitous joint model are discussed in detail in the FLAC User's Manual.

Four properties of the Mohr-Coulomb solid are the cohesion, dilation angle, tension limit, and angle of internal friction. The joints have four properties, including the angle of the parallel joints embedded in the solid (with respect to the horizontal), the joint cohesion, the joint tension limit, and the joint friction angle. Note that since the joints are ubiquitous plastic slip planes, the ubiquitous joint model does not have a crack density parameter or joint spacing associated with it.

The values for the thermal properties listed in Table 1 are the same as those used by Lee (1995). The thermal conductivity and specific heat values for wet tuff

Table 1. Rock property values used to model the LBT.

\begin{tabular}{lcl}
\hline Physical property & Value & Source \\
\hline & Thermal Properties & \\
Thermal conductivity & $2.10 \mathrm{~W} /\left(\mathrm{m}-{ }^{\circ} \mathrm{K}\right)$ & DOE (1991) \\
Specific heat & $840 \mathrm{~J} /\left(\mathrm{kg}-{ }^{\circ} \mathrm{K}\right)$ & DOE (1991) \\
Thermal expansion coefficient & $9.1 \times 10^{-6} /{ }^{\circ} \mathrm{K}$ & Estimate \\
& Mechanical Properties & \\
Bulk modulus & $27 \times 10^{9} \mathrm{~Pa}$ & Zimmerman (1986) \\
Shear modulus & $14 \times 10^{9} \mathrm{~Pa}$ & Zimmerman (1986) \\
Density & $2300 \mathrm{~kg} / \mathrm{m}^{3}$ & Blair et al. (1996); \\
& $22 \times 10^{6} \mathrm{PA}$ & Roberts (1996) \\
Cohesion & $10 \mathrm{deg}$ & Arulmoli et al. (1987) \\
Dilation angle & $6 \times 10^{6} \mathrm{~Pa}$ & FLAC User's Manual \\
Tension limit & $29 \mathrm{deg}$ & Estimate \\
Internal angle of friction & $10 \mathrm{and} 85 \mathrm{deg}$ & Arulmoli et al. (1987) \\
Joint angle (cc from horizontal) & $6 \times 10^{5} \mathrm{~Pa}$ & Estimate \\
Joint cohesion & $5 \times 10^{5} \mathrm{~Pa}$ & Estimate \\
Joint tension & $31 \mathrm{deg}$ & Estimate \\
Joint friction angle & & Price et al. (1993) \\
\hline
\end{tabular}


are given in the U.S. Department of Energy's Reference Information Base (DOE, 1991). Future modeling may use different values as laboratory data become available from tests on small (about $1 \mathrm{~m}$ on a side) blocks of Topopah Spring tuff.

The bulk modulus and shear modulus values listed in Table 1 were determined from elastic wave velocity measurements, both preliminary measurements on small blocks of Topopah Spring tuff and also velocities reported from the G-tunnel heated block experiment (Zimmerman et al., 1986). As static values of moduli become available from laboratory tests on 1-m blocks of Topopah Spring tuff, this information will be included in future modeling. Preliminary measurements show that fractured tuff may have elastic moduli that are an order of magnitude lower than the values shown in Table 1. FLAC modeling was conducted to explore the implications of this possibility.

The density for tuff listed in Table 1 is from laboratory measurements on Topopah Spring tuff samples from the LBT site (Blair et al., 1996; Roberts, 1996). The tuff had a skeletal density of $2.56 \mathrm{~g} / \mathrm{cm}^{3}$ and a bulk density of $2.27 \mathrm{~g} / \mathrm{cm}^{3}$. The bulk density is appropriate for representing the density of the entire large block.

Values for the ubiquitous joint model parameters were mainly set using information from Arulmoli et al. (1987). Their finite-element thermal-mechanical modeling included ubiquitous joint modeling, and they report the model values they used to represent $80 \%$ saturated, devitrified Topopah Spring tuff. In Table 1, values for the cohesion of the solid and the internal angle of friction for the solid are those used by Arulmoli et al. (1987). They used 9.0 MPa for the tension limit of the tuff, but this value is probably too high for the highly fractured large block. We chose 6.0 MPa for the FLAC modeling. This value will be adjusted in future modeling, as laboratory data become available. Although Arulmoli et al. (1987) do not report values for the dilation angle for tuff, the FLAC User's Manual says that values of about 10 to $15 \mathrm{deg}$ would be typical for concrete or sand. We chose $10 \mathrm{deg}$ for the FLAC modeling. We did not perform detailed sensitivity studies to determine how sensitive the modeling results were to the exact choice of values for the parameters describing rock properties.

Preliminary results of fracture mapping for the LBT show that most fractures in the block are subvertical, and a major subhorizontal fracture is found near the top of the block. A value of about $85 \mathrm{deg}$ is appropriate for representing the joint angle for subvertical fractures, and $10 \mathrm{deg}$ is representative of subhorizontal fractures. For the joint cohesion, Arulmoli et al. (1987) used 1.0 and $0.05 \mathrm{MPa}$. An intermediate value of $0.6 \mathrm{MPa}$ was chosen for the FLAC modeling. Arulmoli et al. (1987) used a joint friction angle of about $39 \mathrm{deg}$. Reported values of the average coefficient of friction for tuff (Price et al., 1993) suggest that 31 deg is 
more appropriate for the joint friction angle; thus, we used this lower value in the FLAC modeling.

In FLAC, the tensile strength is limited by cohesion and the friction angle. If the tension limit exceeds the value found by dividing the cohesion by the tangent of the friction angle, the tension limit is reset to that value. Thus, the maximum value of the joint tension limit found using a joint cohesion of $0.6 \mathrm{MPa}$ and a joint friction angle of $31 \mathrm{deg}$ would be about $1 \mathrm{MPa}$. The default joint tension limit in FLAC is zero, but that would be too small a value. The FLAC modeling used an intermediate value of $0.5 \mathrm{MPa}$ for the joint tension limit.

\section{ABAQUS Models}

The second method we considered is the $3 \mathrm{D}$ finite-element method, and the code ABAQUS was used to evaluate this method. ABAQUS is a threedimensional code with capability for time-dependent analysis of thermal and mechanical behavior.

The numerical model is weakly coupled in the sense that the temperature field produces thermal stresses, but these stresses do not in turn influence temperatures. The temperature field is calculated as a function of time from a thermal diffusion model. The sides and top of the block are assumed to be insulated. The ground extending a few meters to either side of the block is assumed to be isothermal. The mechanical model uses the temperature field at various times to apply thermal loading. All of the surface stresses are assumed to be zero. Only one-quarter of the block is modeled; therefore, the two symmetry planes are given boundary conditions of zero displacement normal to the plane. The bottom of the model lies several meters below the ground surface, and it is also a zero displacement boundary. Up to 75 days, the temperature effects of the heating do not extend beyond $1 \mathrm{~m}$ from the block; therefore, the model boundaries have little effect on the thermomechanical behavior of the large block itself.

ABAQUS processes input in a batch fashion. The thermal model (therm.inp) is an independent input file, which writes a results file of nodal temperatures at specified time steps. The mechanical model (mech.inp) reads the results of the thermal model and calculates an equilibrium displacement field. The two models use the same nodes and linear, brick elements. The procedure for running ABAQUS is to first create a file that provides information about the grid used, the mechanical and thermal properties of the rock to be simulated, the mechanical boundary conditions, and the initial conditions. This file is similar to the input file used for the FLAC code. The following paragraphs discuss the input used for the simulations conducted for this study. 


\section{Time Steps}

The thermal model in ABAQUS is run with one step and 75 increments, where each increment is one day. The mechanical model is run in seven steps. Each step represents 10 days. The mechanical problem is static, so each step is one increment long. All together, the model contained 3912 nodes and 2864 elements. The thermal model took about $50 \mathrm{~min}$ to execute 75 time steps of one day each on a Sparc10 workstation. The mechanical model was computed every 10 days, and the execution time was about $30 \mathrm{~min}$ on a Sparc10 workstation. Output files were stored after every time step.

\section{Grids, Nodes, and Elements}

The nodes are divided into a block set and a ground set. The grid for the faces of the block perpendicular to the heaters is the same as that used in thermalhydrological simulations of the LBT (Lee, 1995) and in the thermal-mechanical FLAC model simulations. The grid for the ground does not extend as far as in the previous models, because those results showed that effects of the heating are of limited extent into the ground. The thermal elements (DC3D8) and the mechanical elements (C3D8R) are paired for thermomechanical problems, in which the temperature field is first computed at different times before solving for mechanical equilibrium.

\section{Material Properties}

ABAQUS requires many of the same material properties as FLAC, and for the simulations conducted in this study, the mechanical and thermal properties input to ABAQUS were identical to those used in the FLAC elastic model and are given in Table 1. In the ABAQUS modeling, an elastic model was used to simulate the large block, and no viscoelastic properties or fracture zones were used.

\section{Initial and Boundary Conditions}

The initial temperature is $20^{\circ} \mathrm{C}$ for both the thermal and mechanical models. Thermal stresses arise as a result of thermal expansion relative to this reference state. The default condition for the temperature problem is that boundaries are insulated. In the model, all boundaries are insulated except the ground surface, which is maintained at $20^{\circ} \mathrm{C}$. The default condition for the mechanical problem is that boundaries are at zero stress. In the model, all boundaries are stress-free except the symmetry planes and the bottom of the model. The load for the thermal problem is the constant temperature heaters. (Modeling the heaters as constant power heat sources requires a Fortran subroutine HETVAL that was not available for this study.) The load for the mechanical problem is the thermal stresses arising from the nonuniform temperature field at different times. 


\section{Output}

The nodal temperatures were placed in a special results file for use by the mechanical model. Also, temperatures along the side of the block parallel to the heaters were specified to be included in the dat ASCII file with other results normally produced by ABAQUS. In the mechanical model, displacements on the outer face parallel to the heaters were specified to be included in the dat file.

\section{FLAC Modeling Results}

Four different 2D FLAC models were run to model the LBT. The first model assumed the large block was a homogeneous elastic solid having the elastic moduli values listed in Table 1. The second model assumed a homogeneous elastic large block, but the values of the bulk and shear moduli were reduced by an order of magnitude to simulate the effect of many fractures in an elastic medium. In the third model, two fractures were simulated in the block by modeling the block as an elastic medium containing one set of vertical grid elements and one set of horizontal grid elements having elastic moduli reduced by 1 order of magnitude. The fourth model simulated these two fractures by using the ubiquitous joint model within these sets of horizontal and vertical grid elements, and representing the rest of the block as a homogeneous elastic medium.

Each of these four models was first brought to initial mechanical equilibrium. The initial maximum unbalanced force had a magnitude of about $10^{6} \mathrm{~N} / \mathrm{m}$ as a result of the maximum stress in the initial mechanical model, $10^{5} \mathrm{~Pa}$, acting on the largest grid element, having $16-\mathrm{m}$ sides. This initial unbalanced force was reduced by about 4 orders of magnitude after 9000 steps, requiring about $4 \mathrm{~min}$ of computer time on a Sparc10 workstation.

\section{FLAC Thermal Results}

For each of the four models, after mechanical equilibrium was attained, FLAC was run in the thermal mode to simulate heating for 75 days. Since the temperature field is not affected by mechanical properties, all of the four models had identical temperatures for any given number of days. Figure 3 shows the temperatures after 1, 10, and 25 days; Figure 4 shows the temperature after 50 and 75 days of heating. Figure 5a shows the temperature profile for the top of the block, and Figure $5 \mathrm{~b}$ shows the profile for the grid element representing the central heater. Lee (1995) shows a similar temperature profile for the heaters (see Figure 1), except that the temperatures in Lee's model are slightly lower at a given time because he does not use an adiabatic boundary condition at the top of the block. 


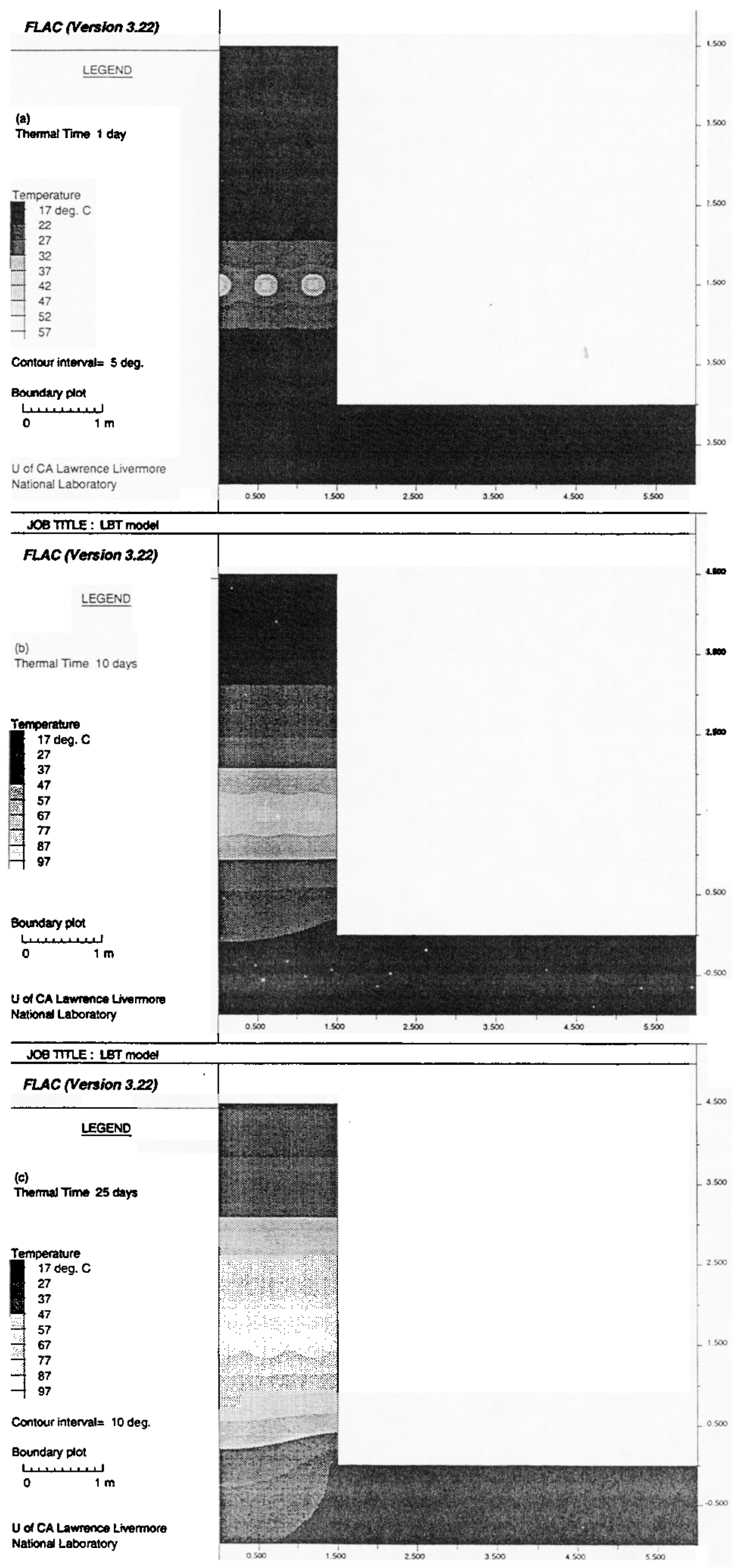

Figure 3. Temperature distributions in the cross section of the large block at (a) 1 day, (b) 10 days, and (c) 25 days after the start of heating, as predicted by the FLAC model. 


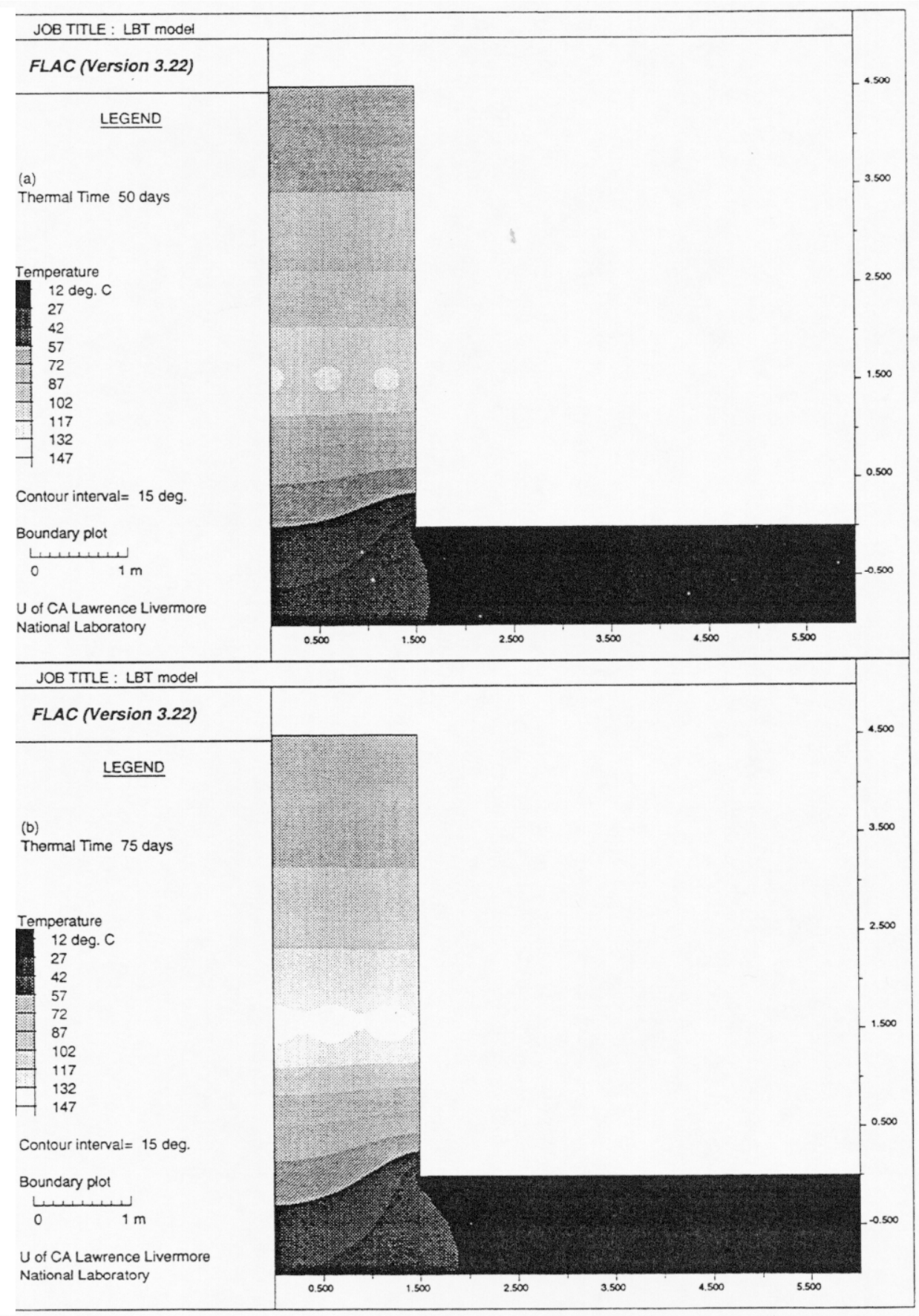

Figure 4. Temperature distributions in cross-section of large block at (a) 50 days and (b) 75 days after the start of heating, as predicted by the FLAC model. 


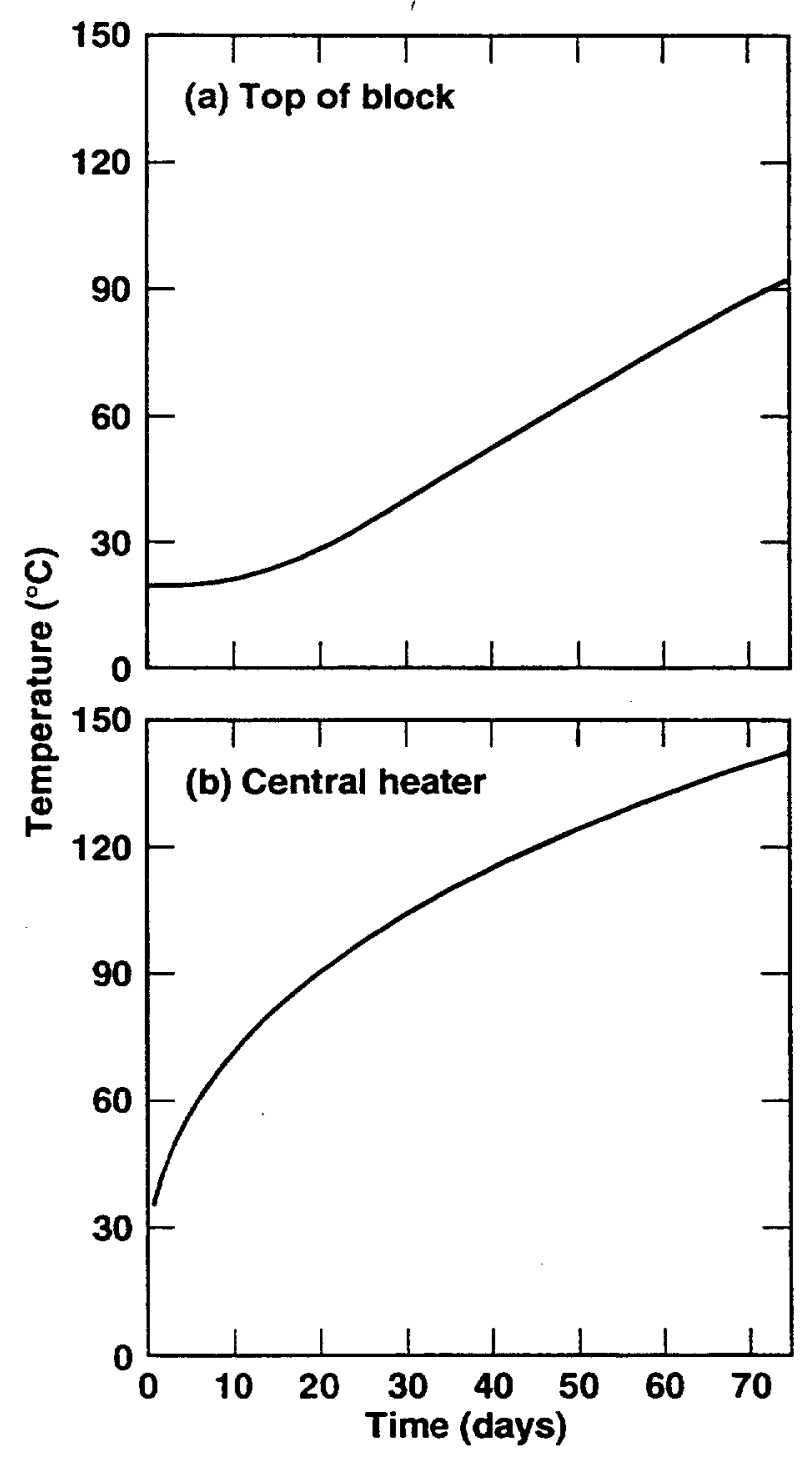

Figure 5. Predicted temperature histories for (a) the top of block and (b) the central heater. 
The figures show that the base of the block and the top $1 \mathrm{~m}$ of the block remain at the ambient temperature of about $20^{\circ} \mathrm{C}$ for the first 10 days of heating, at which time the heaters are at about $70^{\circ} \mathrm{C}$. The isotherms are horizontal and are symmetrical above and below the heater plane for the first 10 days of heating.

By the 25th day of heating, the top of the block has reached a temperature of about $35^{\circ} \mathrm{C}$, and the heaters are at about $95^{\circ} \mathrm{C}$. The isotherms are horizontal except for within about $30 \mathrm{~cm}$ of the heaters and the region near the bottom corner of the block where the adiabatic boundary condition for the side of the block meets the isothermal boundary condition for the ground surface. These contours at the base of the block could be made more horizontal if the ground surface within about $1 \mathrm{~m}$ of the base of the block were adiabatic, which suggests that insulation should be used on the ground near the base of the block for the LBT. After 25 days of heating, the temperature gradient is somewhat steeper below the heaters than above the heaters, because there is no heat flow out the top of the block. The base of the block is about 30 to $50^{\circ} \mathrm{C}$ at this time. No dryout zone forms in the first 25 days of heating, except for right in the plane of the heaters.

Note that the temperature change in the heater zone is very high for the first 10 days of heating, about $50^{\circ}$ as the heaters increase from 20 to $70^{\circ} \mathrm{C}$, and is only half as much for the next 15 days of heating as the heaters increase to about $95^{\circ} \mathrm{C}$ on the 25th day of heating. This result suggests that stresses due to thermal expansion of the rock would be developed at a fairly early time in the 75 days of heating.

The top of the block reaches $60^{\circ} \mathrm{C}$ at about the 45 th day of heating, assuming the top is adiabatic. This time is probably about 20 to 30 days earlier than in the LBT, and some future modeling with a different boundary condition will be performed to better simulate the top of the block. Lee (1995) used an isothermal top boundary set at $60^{\circ} \mathrm{C}$, but this results in heat flow downward from the top of the block, for the first 30 days in his hydrothermal modeling.

After 50 days of heating, the isotherms are horizontal above the heater zone, and slightly distorted and closer together below the heater zone. The base of the block is about 40 to $60^{\circ} \mathrm{C}$, the top of the block is slightly above $60^{\circ} \mathrm{C}$, and the heaters are at about $125^{\circ} \mathrm{C}$. Temperatures above the boiling point of water are found extending to about $50 \mathrm{~cm}$ above and $30 \mathrm{~cm}$ below the heaters, suggesting that a dryout zone nearly $1 \mathrm{~m}$ wide could form in the large block at this time. Between the 25th and 50th day of heating, temperatures at the base of the block have changed only about 10 to $20^{\circ} \mathrm{C}$, while temperatures of the heaters and the top of the block change by about $30^{\circ} \mathrm{C}$. The stresses and displacements due to the thermal loading are expected to be higher above the heaters compared with those 
in the region below the heaters. Note that the temperatures beyond about $1 \mathrm{~m}$ below the base of the block remain low even after 50 days of heating in the block.

The heaters reach a temperature of about $140^{\circ} \mathrm{C}$ after 75 days of heating. The temperature $1 \mathrm{~m}$ below the base of the block is about $40^{\circ} \mathrm{C}$, and temperatures of regions more than about $0.5 \mathrm{~m}$ away from the block remain at the original temperature of $20^{\circ} \mathrm{C}$. Temperatures remain at about $20^{\circ} \mathrm{C}$ for regions more than about $2 \mathrm{~m}$ below the block. Lee (1995) shows a similar temperature field in his hydrothermal modeling. The similarity of the temperature fields for the thermalmechanical and thermal-hydrological modeling assures that appropriate parameters for simulating the LBT were used in the FLAC modeling. It also suggests that results of Lee's modeling could be used as input for future FLAC modeling to simulate coupled hydrological-thermal-mechanical processes.

\section{FLAC Mechanical Results}

Once the temperature field was determined for different heating times, FLAC was run in the mechanical mode to determine what stresses and displacements developed in each of the four different mechanical models. Each of these runs required about 7000 steps and less than $10 \mathrm{~min}$ of computer time on the Sparc10 workstation. The stresses and displacements differ for different heating times; this section concentrates on results from 75 days of heating.

Figure 6 shows the horizontal and vertical displacements, and Figure 7 shows the stresses after 75 days of heating for the first FLAC model in which the large block was represented as a homogeneous elastic medium having a bulk modulus of $27 \mathrm{GPa}$ and a shear modulus of $14 \mathrm{GPa}$. In this plot, $\sigma_{x x}$ is the stress in the $x$ direction applied to a plane whose normal is in the $x$ direction. Similarly, for $\sigma_{y y}$ and $\sigma_{x y}$, the first index indicates the stress direction, and the second indicates the direction normal to the plane.

This model shows that the maximum horizontal displacement occurs in the heater plane, at the outside edge of the model, and has a magnitude of about 2 $\mathrm{mm}$. Vertical displacement is highest near the top of the block with a magnitude of about $5 \mathrm{~mm}$, decreasing to about $0.5 \mathrm{~mm}$ at the base of the block. Vertical displacement contours are approximately horizontal.

Both the $\sigma_{x x}$ and the $\sigma_{y y}$ plots show that the region around the central heater develops compressive stresses with magnitudes up to about $8 \mathrm{MPa}$. The $\sigma_{x x}$ plot also shows compressive stresses of this magnitude developing at the bottom corner of the block, while the $\sigma_{y y}$ plot shows tensile stresses having magnitudes up to $10 \mathrm{MPa}$ developing at the outer edge of the model in the plane of the heaters. This difference is significant because the stress level is on the order of the tensile strength of the welded tuff, which is about $6 \mathrm{MPa}$, and much greater than 


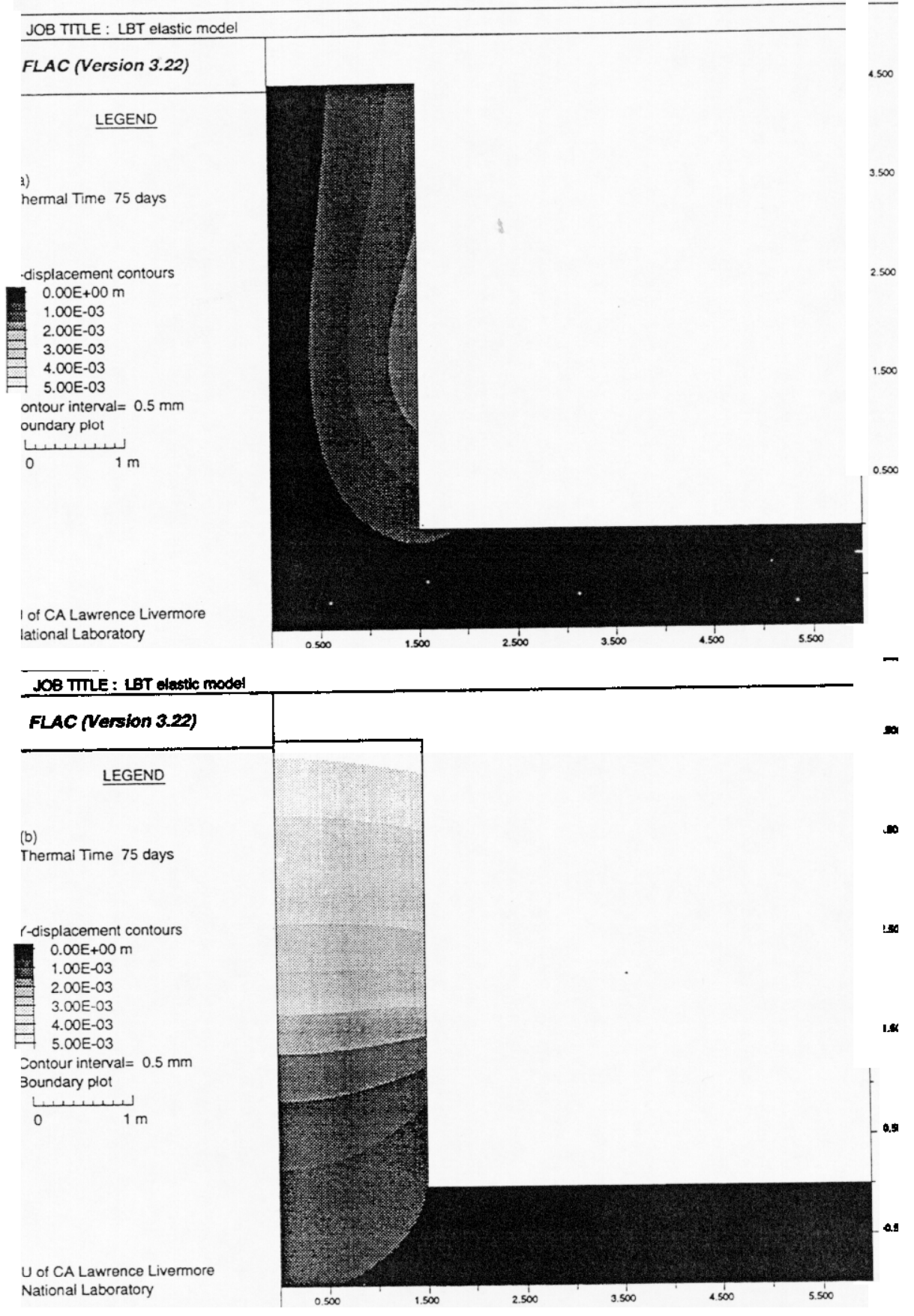

Figure 6. (a) Horizontal and (b) vertical displacements for the large block predicted using the FLAC code and assuming the large block behaves as an elastic continuum. 


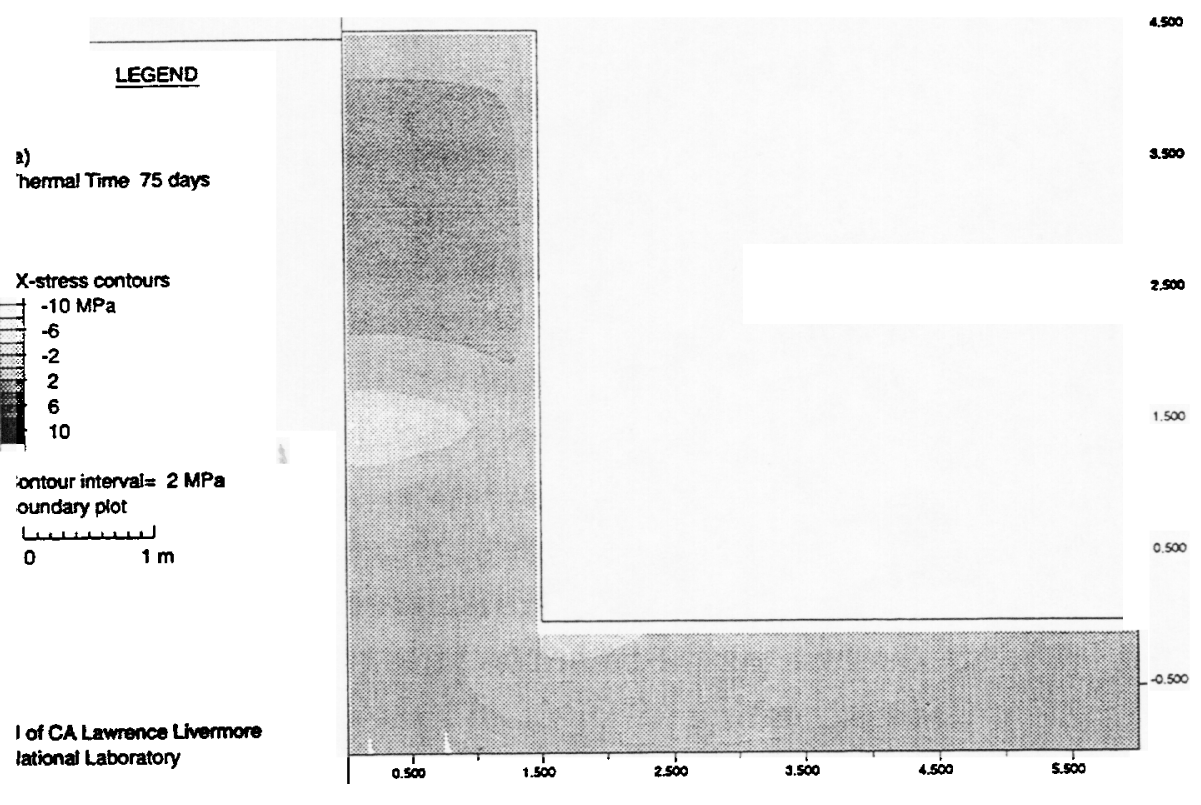

JOB TITLE : LBT elastic model

Figure 7. Contours of the (a) $\sigma_{x x}$ (b) $\sigma_{y y}$ and (c) $\sigma_{x y}$ stress values predicted for the large block using the FLAC code and assuming the large block behaves as an elastic continuum.

$\frac{\text { JOB TITLE : LBT elastic model }}{\text { FLAC (Version 3.22) }}$

(b)

Thermal Time 75 days

$\cup$ of CA Lawrence Livermore National Laboratory

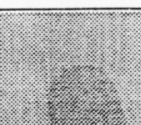

JOB TITLE : LBT elastic mode

FLAC (Version 3.22)

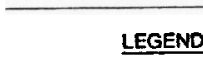

(c)

\section{LEGEND}

Thermal Time 75 days

$X Y$-stress contours

$\Rightarrow-10 \mathrm{MPa}$

$\Rightarrow-6$

$-2$

2
6
10

Contour interval $=2 \mathrm{MPa}$ Boundary plot inchen 
the tensile strength of any fractures in the block, which is estimated to be less than $1 \mathrm{MPa}$ (see Table 1). The $\sigma_{x y}$ plot for this elastic model shows that shear stresses having magnitudes up to about $4 \mathrm{MPa}$ may develop in the plane of the heaters. Plots of stresses for 25 days of heating the elastic model (not shown) are essentially the same as the plots for 75 days. The displacements are slightly lower, with a maximum of 1-mm horizontal displacement after 25 days of heating and a maximum of about $2.2-\mathrm{mm}$ vertical displacement. The displacement contours are similar in shape for 25 days of heating compared with those for 75 days of heating, except that the very top of the block is slightly less disturbed. Note that the displacements and stresses develop comparatively early in the heating, because the rates of temperature changes are higher early in the 75 days of heating.

The second FLAC mechanical model represented the large block as a homogeneous elastic medium having lower elastic moduli than the first model. We used a bulk modulus of $2.7 \mathrm{GPa}$ and a shear modulus of $1.4 \mathrm{GPa}$. Initial results of mechanical measurements made in the laboratory for 1-m blocks of tuff from Fran Ridge suggest that these values may be appropriate for representing the highly fractured mass of rock that is the large block. Horizontal and vertical displacements (not shown) after 75 days of heating for this second model were identical to those for the first model, because the thermal expansion coefficient controls displacements and the same value was used for this parameter throughout the FLAC modeling.

For linear elasticity, we expected stresses for this second model to simply be reduced by an order of magnitude from those found for the first elastic model. Results of this modeling (not shown) found no significant compressive stresses or shear stresses developing anywhere in the model and very small tensile stresses $(<2 \mathrm{MPa})$ developing in the heater plane at the outer edge of the model. In this second model, the block is so compliant that it cannot build up significant stresses. An important implication of these results is that the presence of many fractures in the large block prevents stress from building to the high levels predicted for a homogeneous, elastic block.

The third and fourth mechanical models were used to simulate the effect of discrete fractures on the thermomechanical behavior. For these simulations, the large block was represented as an elastic medium containing one horizontal set of grid elements and one vertical set of grid elements in which the properties were changed to simulate a horizontal and a vertical fracture. In the third model, these sets of grid elements were represented as elastic media with bulk and shear moduli lowered by 1 order of magnitude with respect to the rest of the block. The fourth model used the ubiquitous joint model for these elements. Figure 8 shows 


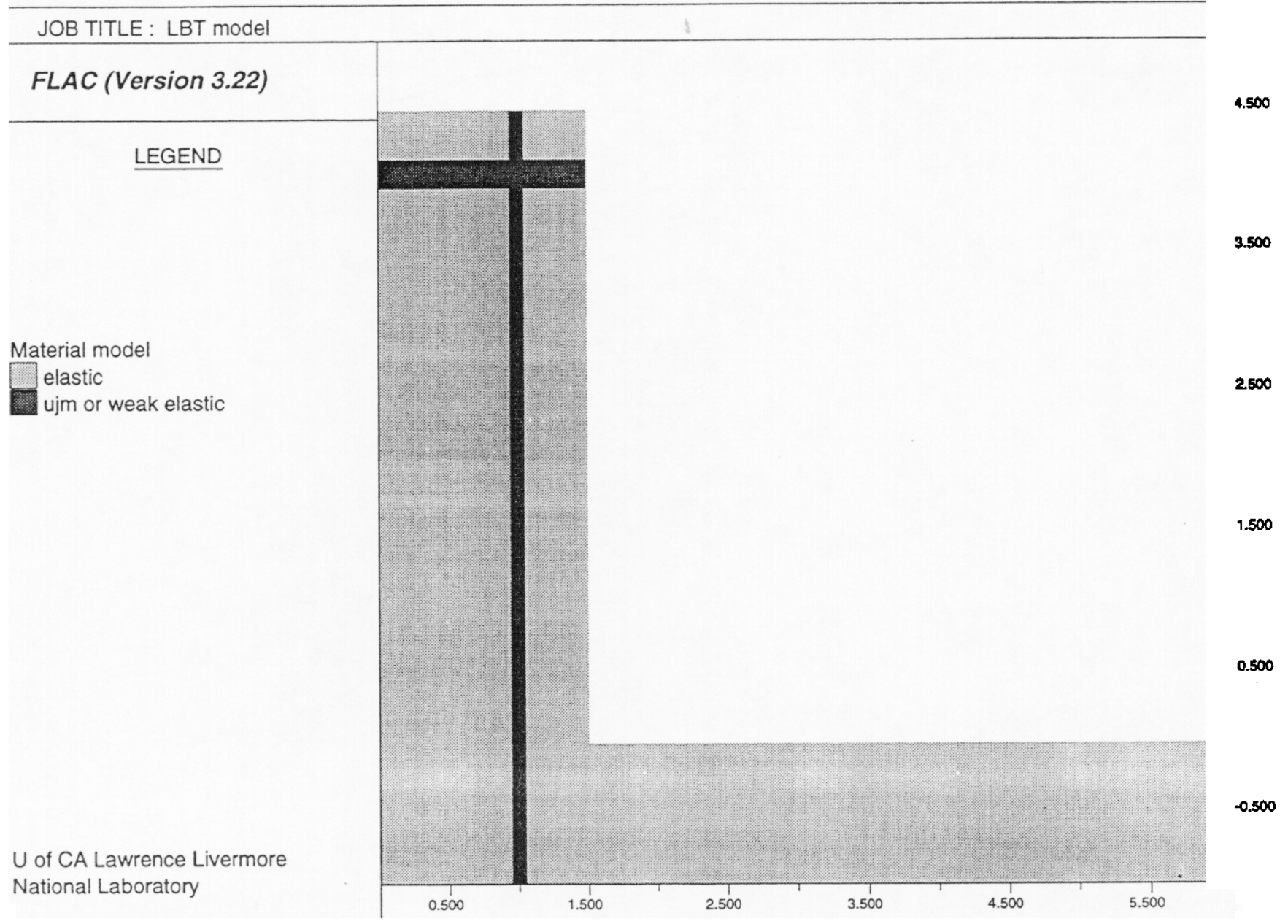

Figure 8. Grid used in FLAC for simulating fractures in the large block. 


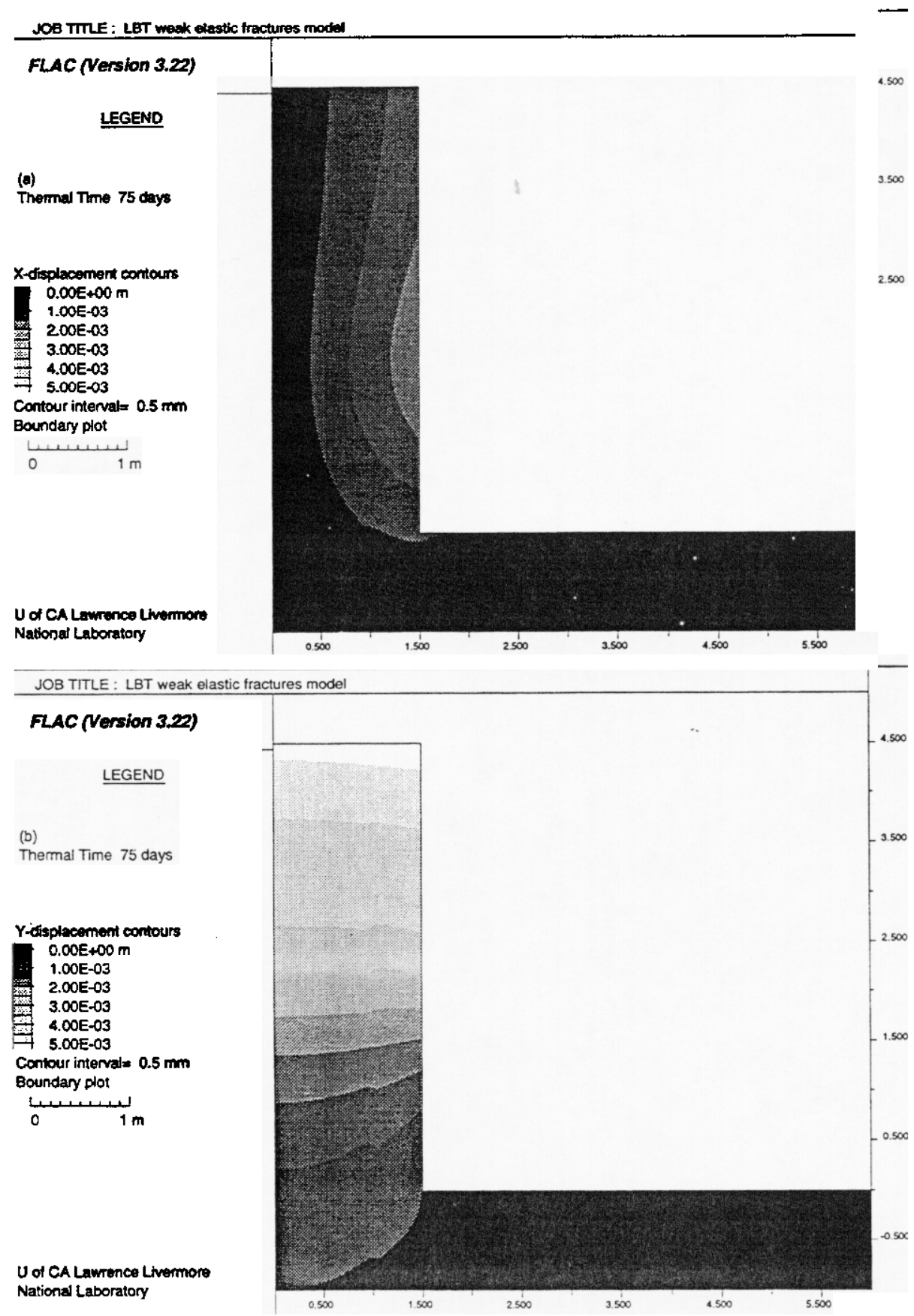

Figure 9. (a) Horizontal and (b) vertical displacements for large block predicted using the third FLAC model. 
Blair et al.

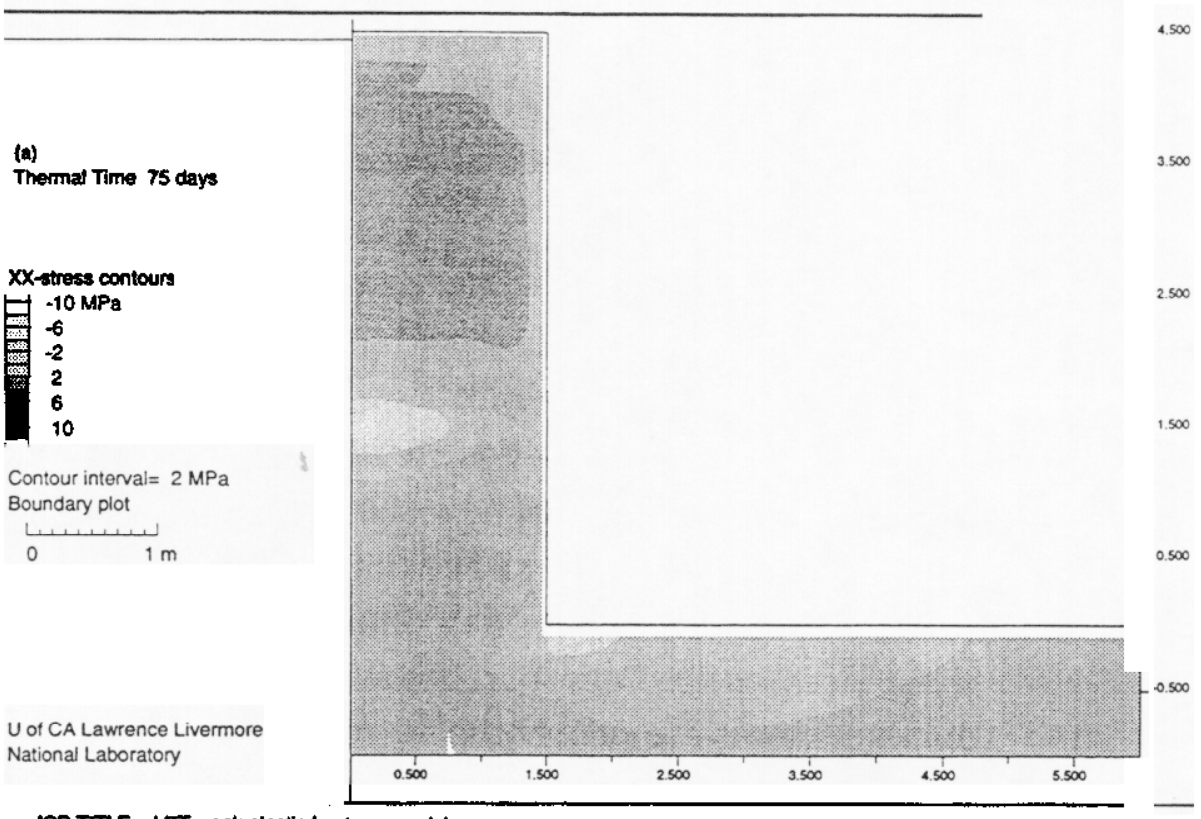

NOE TITE: LBT
FLAC Nersion 3
LEGEND
(b)
Thermal Time 75 days

Figure 10. Contours of the (a) $\sigma_{x x}$, (b) $\sigma_{y y}$, and (c) $\sigma_{x y}$ stress values predicted for the large block using the FLAC code and assuming the large block behaves as an elastic continuum.

\section{$\rightarrow 10 \mathrm{MP}$ \\ $-6$ \\ -2
2
6 \\ 10}

Contour interval $=2 \mathrm{MPa}$ Boundary plot

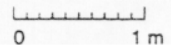

U of CA Lawrence Livermore Nationa: Laboratory

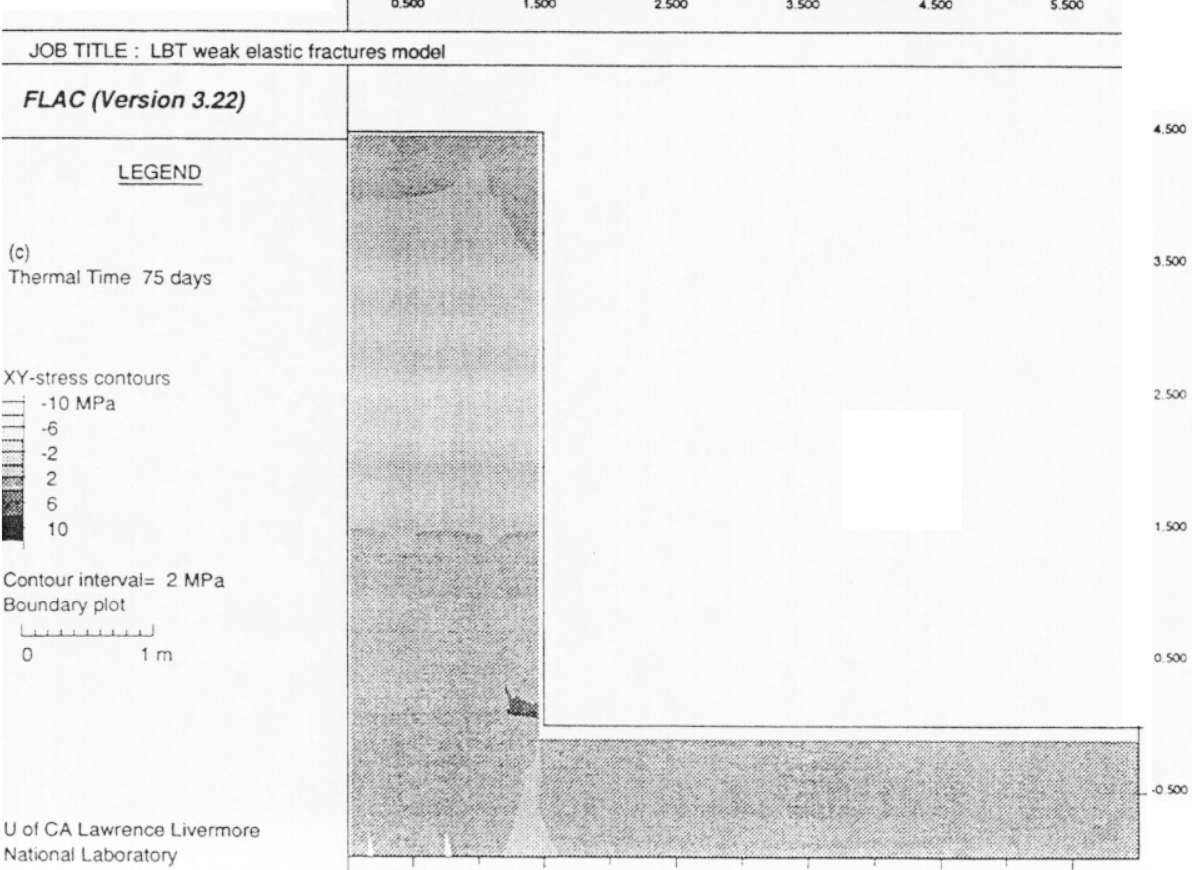


the elements that represent fractures, located in a horizontal line about $0.5 \mathrm{~m}$ below the top of the block and a vertical line about $1 \mathrm{~m}$ from the center of the block.

Figures 9 and 10 show the displacement and stress results for the third model for 75 days of heating. The $\sigma_{x x}$ plot is nearly the same as that for the original elastic model. The $\sigma_{y y}$ plot is almost the same as that for the first elastic model, except that the stress field is slightly distorted by the vertical fracture zone. Most of the compressive stress near the central heater ( 4 to $6 \mathrm{MPa}$ ) and most of the tensile stress at the outer edge of the model in the heater plane ( $>8 \mathrm{MPa})$ are already present after one day of heating (not shown). The $\sigma_{x y}$ plot shows that shear stresses are very low, below $2 \mathrm{MPa}$, for this model. The horizontal displacements are nearly the same as those found in the first elastic model, but the vertical displacements show contours that are offset slightly along the vertical fracture. Magnitudes of maximum displacements are the same for this model and the first elastic model.

The fourth model, which used the ubiquitous joint model to represent the horizontal and vertical fractures, had displacement results (not shown) that were nearly the same as those found using the third mechanical model-i.e., horizontal displacements the same as in the original elastic model and vertical displacements offset a small amount along the vertical fracture. The $\sigma_{x y}$ results for the fourth model (not shown) were about the same as results for the third model (Figure 10c). Figure 11 shows the $\sigma_{x x}$ and $\sigma_{y y}$ plots for the fourth model. These differ from results for the third model. Stresses are somewhat lower but are affected more by the presence of the vertical fracture. These results imply that fractures in the block have a strong effect on the distribution as well as the magnitudes of stresses.

\section{ABAQUS Modeling Results}

This section presents temperatures, normal stresses, and normal displacements for 3D ABAQUS simulations at 10, 20, and 60 days. The results are presented graphically as perspective diagrams of the large block. The diagrams show the perspective of looking at the outside of the block from the point $(1,2,2)$. Only one-quarter of the block is displayed, and the two back surfaces are symmetry planes. Note that the back surface perpendicular to the long axis of the heaters corresponds to the 2D cross section modeled using FLAC. The figures showing the $3 \mathrm{D}$ views are grouped into two sets. The first set (Figures 12-14) shows predicted contours of temperature, and normal stresses at 10,20, and 60 days, respectively. In these figures, normal stresses on the faces perpendicular to the 1,2 , and 3 axes are denoted by S11, S22, and S33, respectively. Stresses are in 


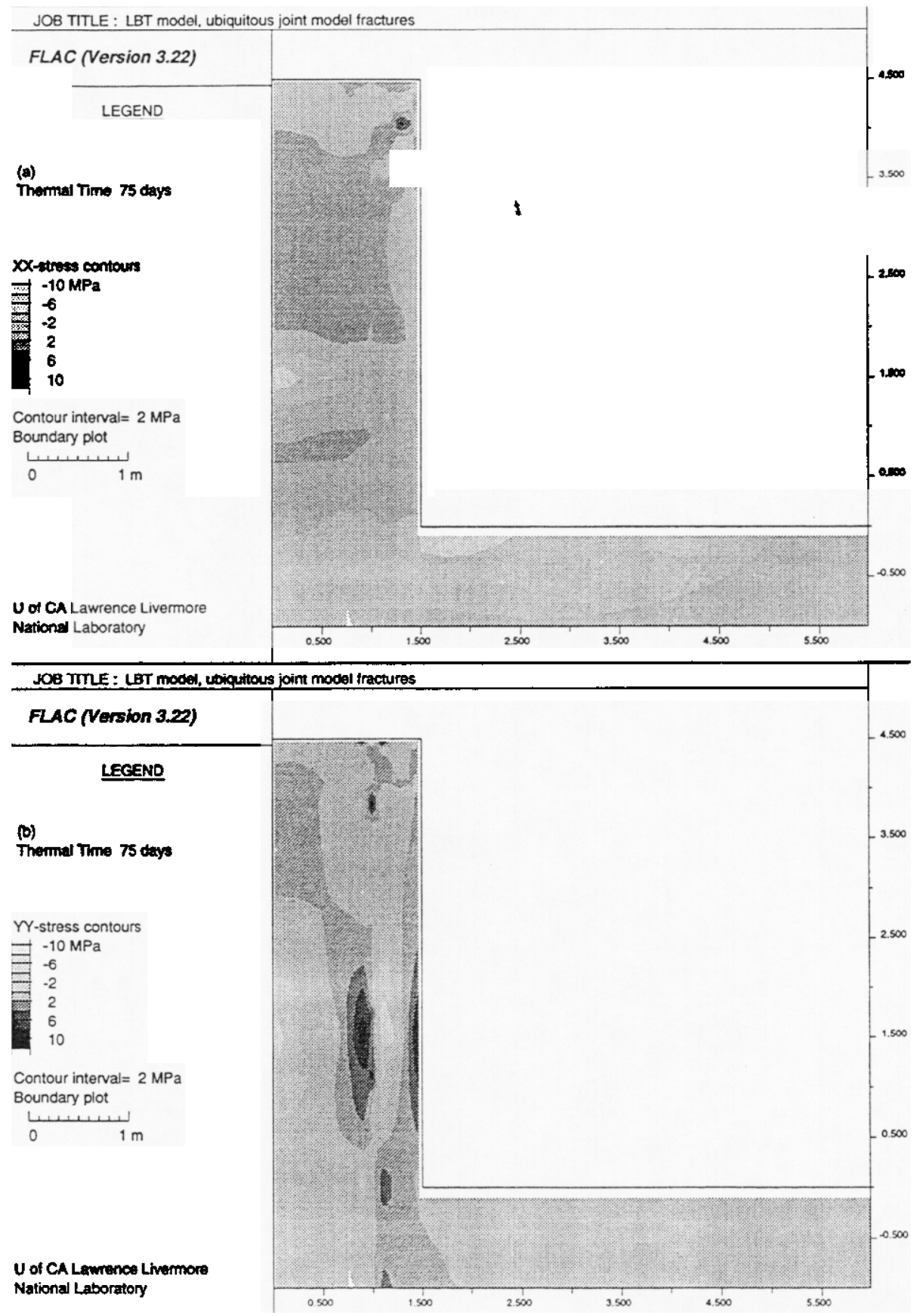

Figure 11. Contours of the (a) $\sigma_{x x}$ and (b) $\sigma_{y y}$ stress values predicted for the large block using the FLAC code and by assuming the large block behaves as an elastic continuum. 

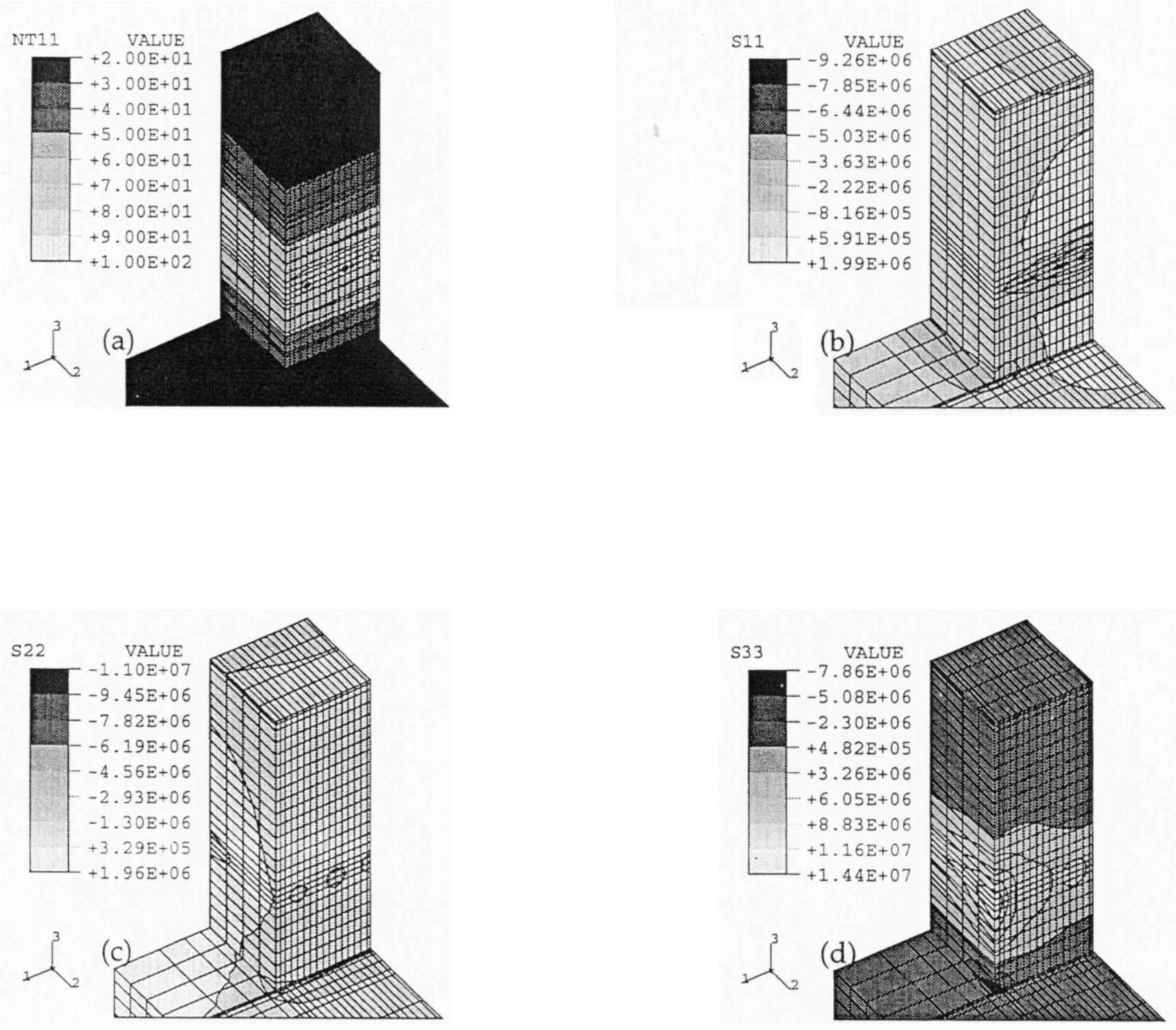

Figure 12. Temperature and normal stresses at 10 days. Heater holes are in the 2 direction. Perspective is from $(1,2,2)$. 

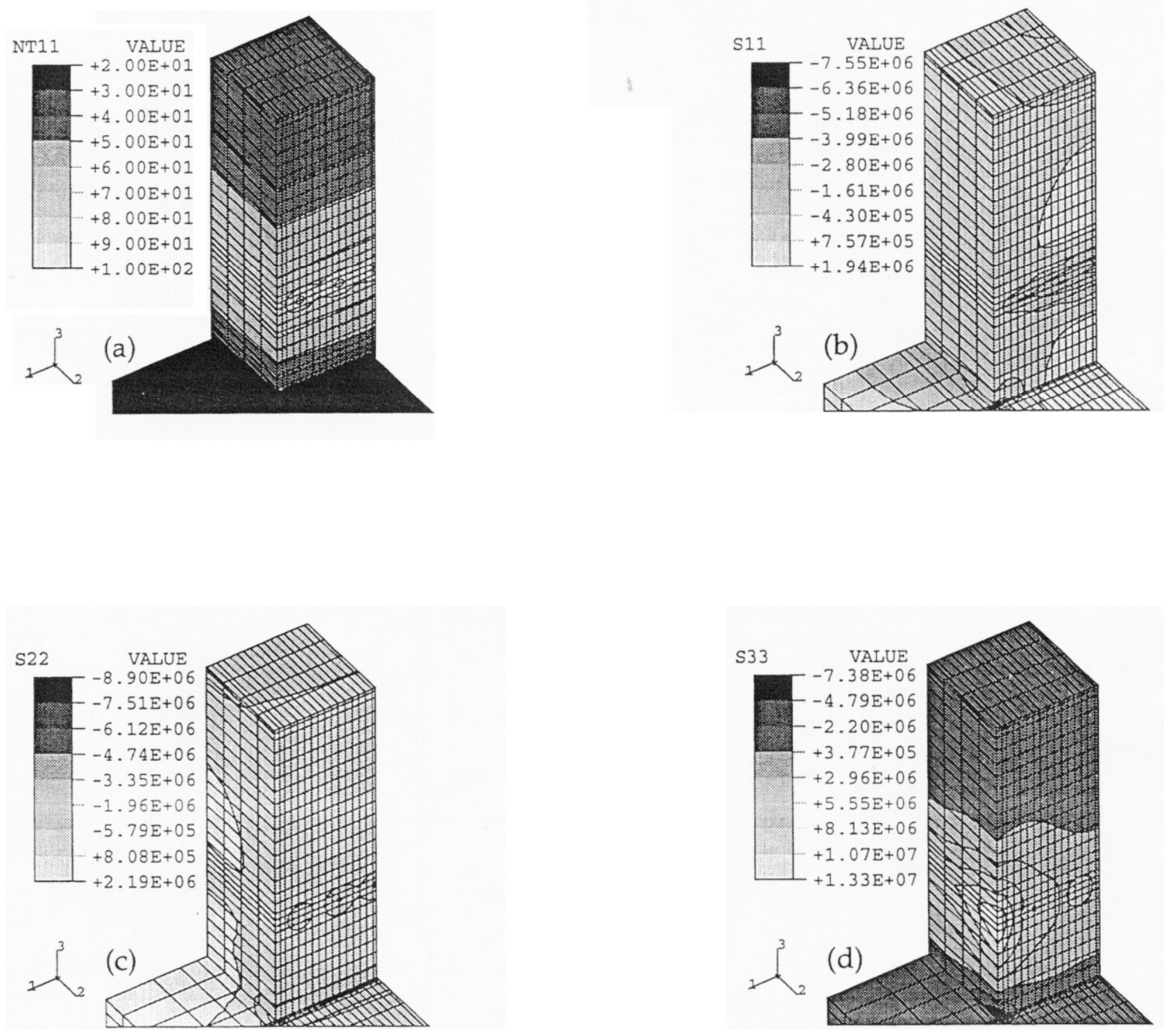

Figure 13. Temperature and normal stresses at 20 days. Heater holes are in the 2 direction. Perspective is from $(1,2,2)$. 

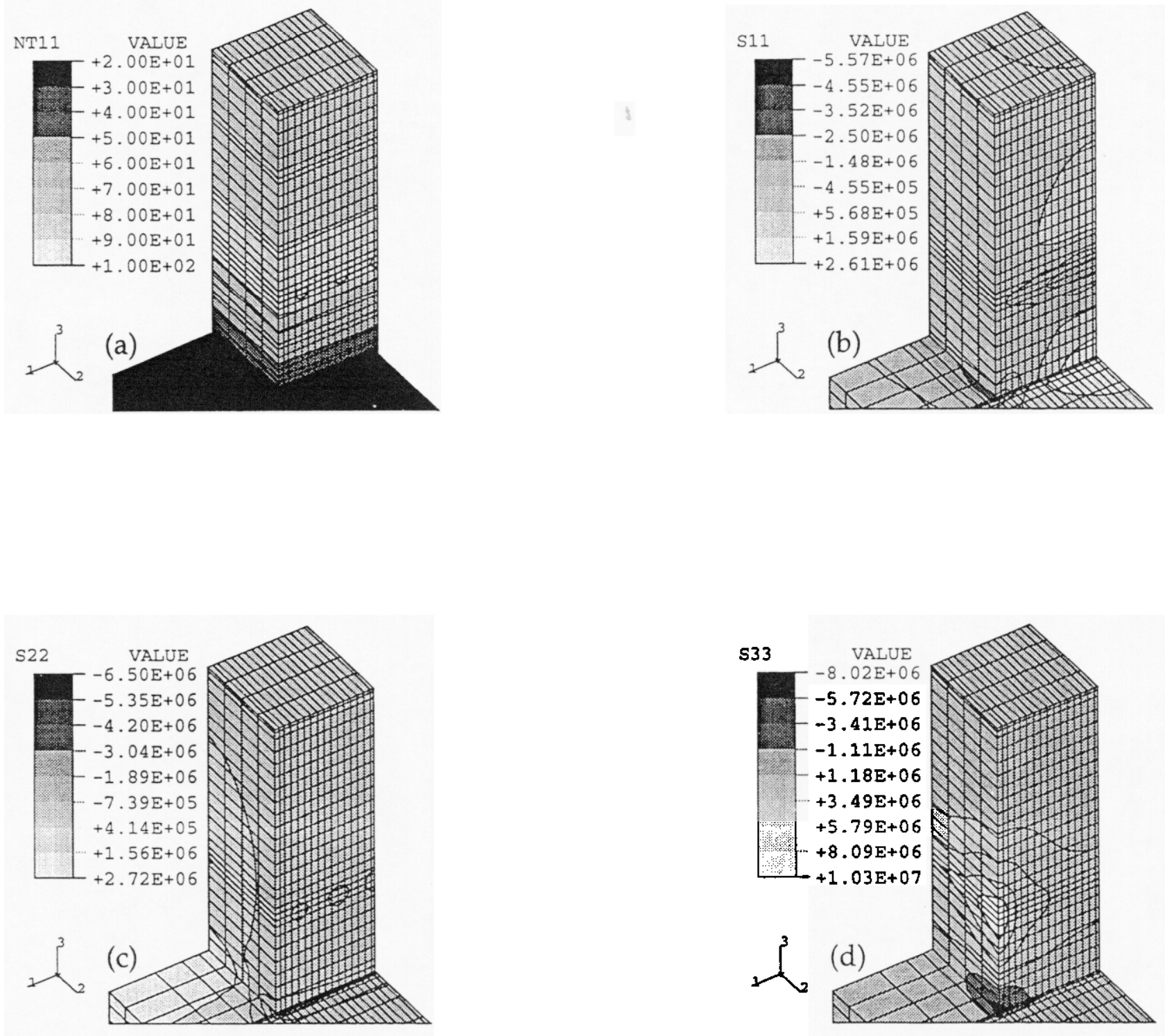

Figure 14. Temperature and normal stresses at 60 days. Heater holes are in the 2 direction. Perspective is from $(1,2,2)$. 

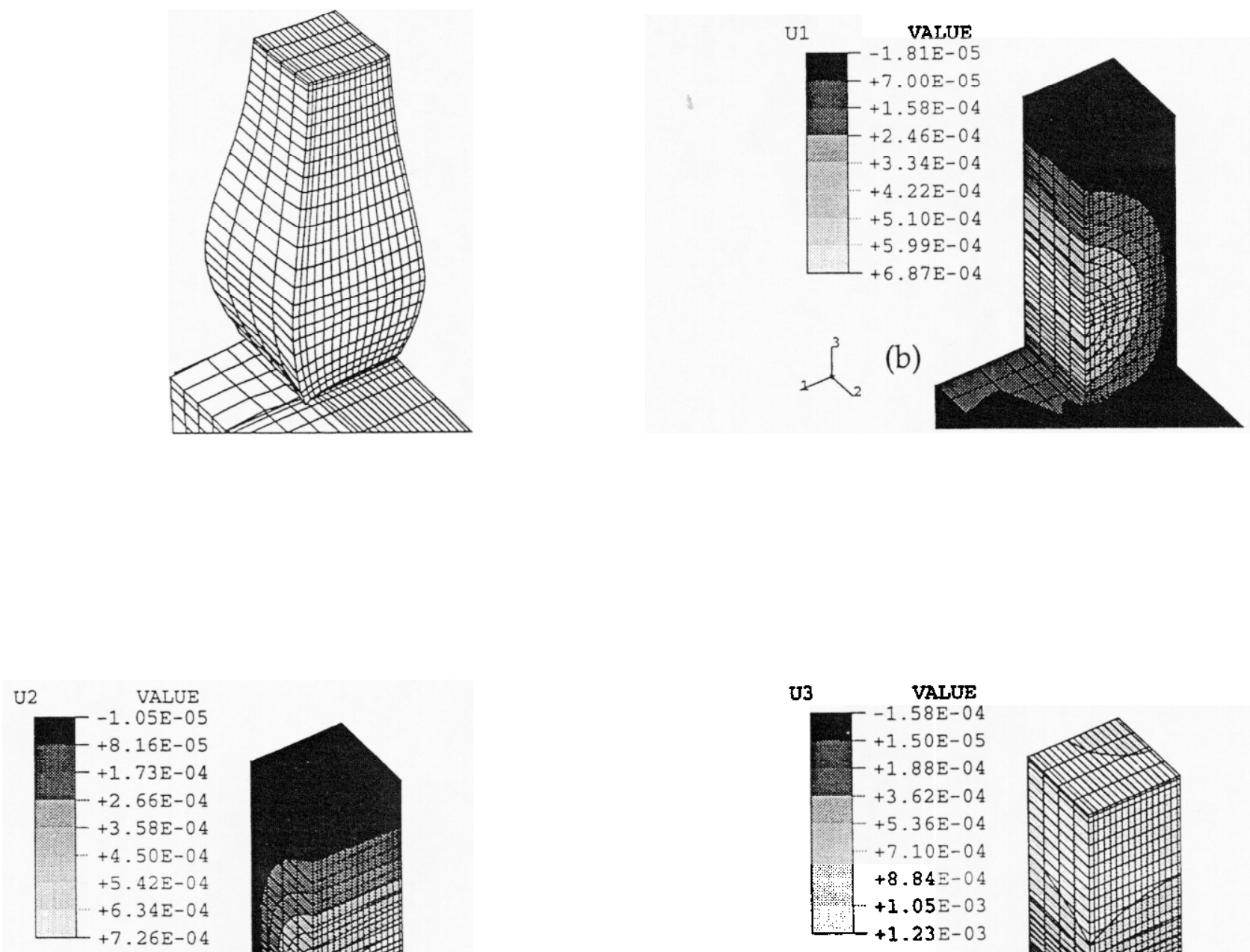

(c)

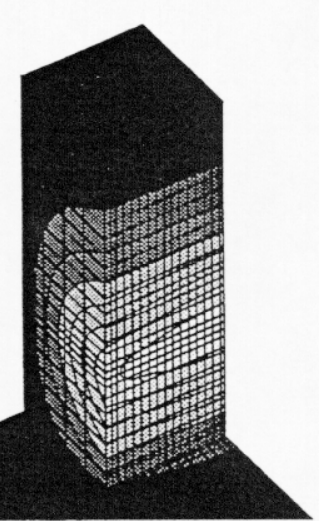

(d)<smiles>CC(C)C</smiles>

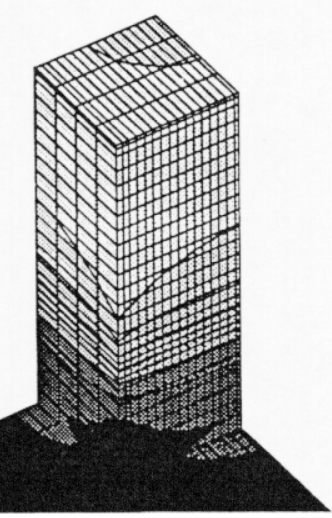

Figure 15. Heated block displacements and displacement components at 10 days. Perspective is from $(1,2,2)$. 

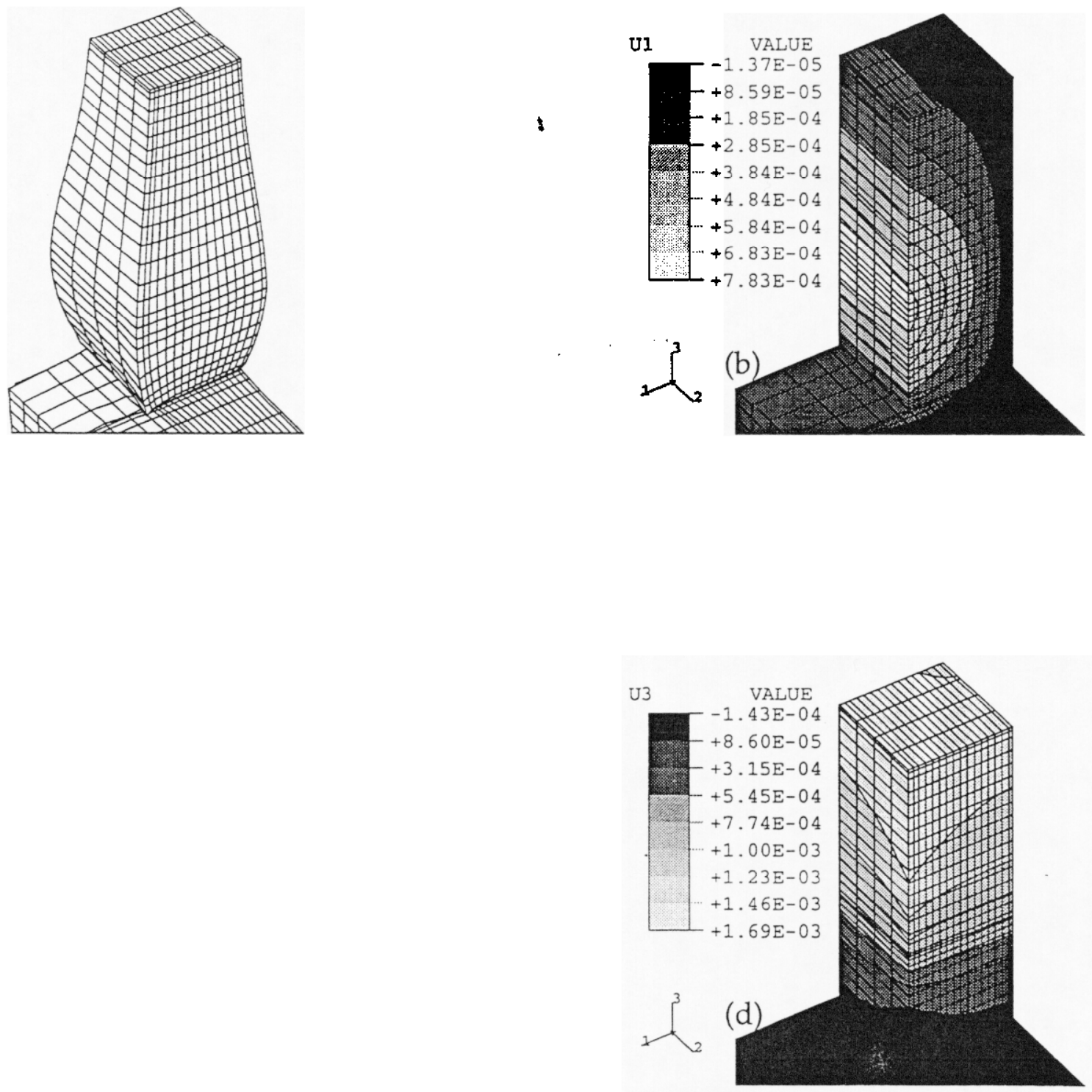

Figure 16. Heated block displacements and displacement components at 20 days. Perspective is from $(1,2,2)$. 

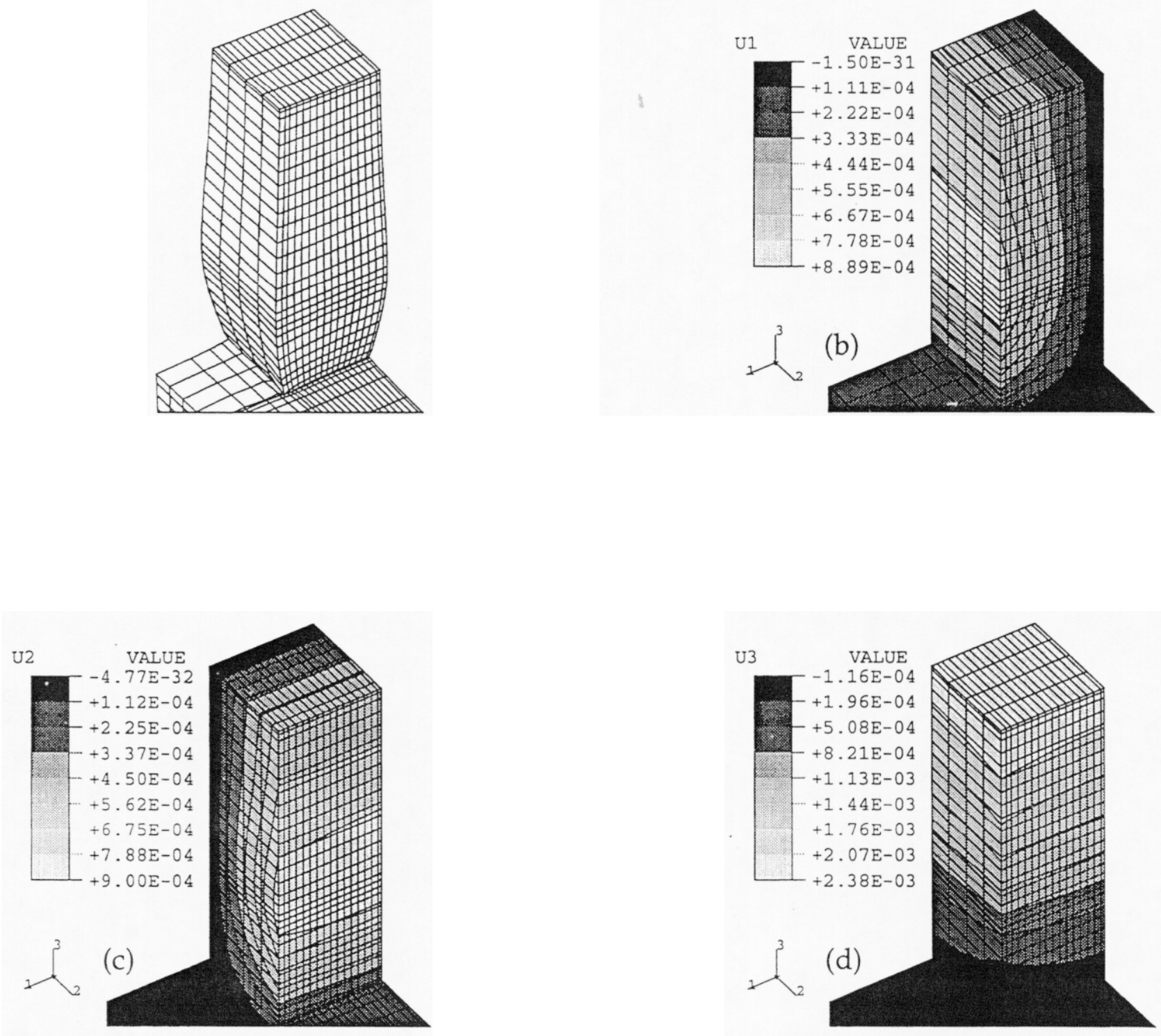

Figure 17. Heated block displacements and displacement components at 60 days. Perspective is from $(1,2,2)$. 
$\mathrm{Pa}$ and temperatures are in ${ }^{\circ} \mathrm{C}$. The second set (Figures 15-17) shows displacements after 10,20, and 60 days of heating, respectively.

These results show that the predicted temperature field is approximately onedimensional because of the insulated boundaries along the sides (Figures 12a14a). The top of the block, which is also an insulated boundary in the model, reaches a temperature of about $65^{\circ} \mathrm{C}$ after 60 days (Figure 14a). An alternative boundary condition for the top of the block would be a boundary in which the heat flux out of the top of the block would be proportional to the difference between the block and ambient air temperature (nominally, $20^{\circ} \mathrm{C}$ ).

The largest of the normal stresses is the vertical stress, S33, at the outside corner of the block near the heater plane (Figures 12d-14d). The largest value shown is about $14 \mathrm{MPa}$, and it occurs at 10 days (Figure 12d). This is consistent with the $2 \mathrm{D}$ analysis, which shows that the higher stresses occur early in the test. The maximum decreases to about $10 \mathrm{MPa}$ at 60 days because the thermal gradients decrease as the block becomes more uniformly heated(Figure 14d). The horizontal stresses parallel and perpendicular to the heaters are almost an order of magnitude smaller than the vertical stress (Figures 12b,c-14b,c).

The second set of figures shows displacements that are predicted for the block (Figures 15-17). In each of these figures, the wire-net diagrams in the upper left corner present total displacements that have been exaggerated for purposes of clarity. Displacements (in $\mathrm{m}$ ) in the 1,2, and 3 directions are given by $\mathrm{U} 1, \mathrm{U} 2$, and U3, respectively. The wire-net diagrams show how the block bulges in all directions, with the largest horizontal displacements normal to the vertical side in the heater plane. The horizontal displacements show at early times an approximate cylindrical shape about a horizontal axis orthogonal to the displacement component (Figure 15b,c), but they become more planar at longer times (Figure 17b,c). Similar patterns are seen in the 2D FLAC analysis for the purely elastic case (e.g., Figure 6a).

\section{Comparison of FLAC and ABAQUS Simulations}

Two- and three-dimensional simulations of the thermal-mechanical behavior of the heat-up portion of the Large Block Test have been conducted. Two different codes were used and in the 2D case several formulations for the constitutive behavior of the block were used, including simulation of fracture zones. The elastic model in two and three dimensions produced the highest stress levels; these occurred during the first 10 days of heating. Tensile stress levels that approach the tensile strength of Topopah Spring tuff were predicted in the plane of the heaters and in the vertical direction in both the 2D and 3D cases for a homogeneous elastic block. 
These simulations assumed nominally stress-free boundaries on the exposed faces of the block. As a result, the displacements (and strains) are dominated by the thermal expansion of the rock mass. The predicted temperature fields agree well with those that were predicted by Lee (1995) using a code that incorporates a more sophisticated thermal-hydrological model. Note that the LBT design incorporates a retention frame that surrounds the sides of the block and applies a nominal confining stress between 0.2 and $0.3 \mathrm{MPa}$ on it. This retention frame would also apply a shear stress on the sides of the block that would oppose the tension generated in the vertical direction and would reduce the level of tensile stress in the block in this direction. However, the amount of reduction is difficult to estimate.

Two simulations were conducted in which discrete fractures present in the large block were simulated. Lower levels of stress were predicted in these simulations, indicating that the presence of compliant fractures may reduce the stress levels.

The 2D, plane strain, FLAC model was constructed in a plane orthogonal to the heater holes. The thermal predictions made with this code show a 2D temperature field near the heaters at early times. At later times, the code predicts a temperature field that is nearly one-dimensional because all the walls are insulated. The temperature fields in the $3 \mathrm{D}$ model were generated using $100^{\circ} \mathrm{C}$ constant-temperature heaters. This approach produced similar temperature fields to those predicted by the 300-W constant-power heaters used in the 2D FLAC model. For example, the temperature at the top of the block is approximately $65^{\circ} \mathrm{C}$ after 60 days in the 3D model and approximately $70^{\circ} \mathrm{C}$ after 55 days (not shown) in the $2 \mathrm{D}$ model.

The differences are greater between the 2D and 3D mechanical models. The plane strain approximation used in the 2D model assumes that the length of the heater direction is long compared with the height and width of the block. Furthermore, the plane strain model does not incorporate the stress-free boundary faces parallel to the model plane. The plane strain model generates a large, compressive normal stress in the heater direction to suppress the thermal expansion in that direction.

Despite these caveats and the differences in the thermal models, the plane strain results and those from the midplane perpendicular to the heaters in the $3 \mathrm{D}$ model are similar because this is a symmetry plane on which the normal displacement is zero in both the 2D and 3D models. Additional analysis not included here shows that in this plane the 3D model predicts that both $\mathrm{S} 11$ and S33 are compressive near the center of the block, just as they are in the 2D model. In fact, the detailed contour patterns and approximate magnitudes for this plane 
in the 3D model match those of the 2D plane strain model rather closely. However, the patterns do not project to the outer surfaces of the block.

\section{Conclusions}

The main results of the modeling can be summarized as follows.

The thermal-mechanical FLAC and ABAQUS modeling produced temperature fields similar to that of Lee (1995), who used a code that contains a more sophisticated thermal-hydrological model. This suggests that the FLAC and ABAQUS codes could be used with a thermal-hydrological model to better investigate coupled processes.

Most of the thermal stress develops in the first 10 days of heating, when the rate of temperature change is highest. The large block would have to be carefully monitored for mechanical changes during this portion of the LBT.

Stress levels are highest in the heater plane and at the bottom outside edge of the block. Tensile stresses are highest at the surface of the block in the plane of the heaters; they are oriented in the vertical direction; and they may be capable of causing tensile fracture. However, results show that the presence of fractures in the large block may reduce the levels of stress in the block below those predicted for a purely elastic continuum. High tensile stresses may still occur locally in the plane of the heaters.

Displacements are highest at the top of the block and at the outside edge of the block in the heater plane, with magnitudes on the order of a few millimeters for both horizontal and vertical directions.

The 2D and 3D simulations are complementary. Results agree for the elastic constitutive model in the symmetry plane at the center of the block. The 2D modeling was faster and was useful for exploring effects of different constitutive models; however, it could not simulate the outside face of the large block where stresses are highest. This limitation occurs because the plane strain assumption is equivalent to assuming that the 2D model lies at the center of the block. Note that most of the instrumentation in the LBT would be located on the outside surface of the block. The 3D modeling required an order of magnitude more in computer time, but it could estimate maximum stresses and displacements everywhere in the block's volume.

\section{Future Work}

Simulation of coupled thermal-hydrological-mechanical processes in fractured rock masses is still in its infancy, and a great deal of development must be done before simulations of this nature produce realistic results. Progress 
toward this goal must be made one step at a time. The most immediate tasks for advancement of this work are as follows.

- The simulations we discussed here must be simply coupled with a thermalhydrological code, so that a more detailed thermal analysis is incorporated.

- More realistic representation of fracture zones should be included in the simulations, and properties of these zones (determined from laboratory and field measurements) incorporated.

- Data on the temperature dependence of thermal expansion should be incorporated.

- Local temperature and stress fields around the heater holes should be computed and the potential for local damage assessed.

- When field data become available, model results must be compared with the temperature and deformation fields observed in the Large Block Test.

\section{References}

Arulmoli et al. (1987), Analysis of Horizontal Waste Emplacement Boreholes of a Nuclear Waste Repository in Tuff, Sandia National Laboratories, Albuquerque, NM, SAND88-7133.

Blair, S. C., J. M. Kelly, O. Pine, R. Pletcher, and P. A. Berge (1996), Effect of Radiation on the Mechanical Properties of Topopah Spring Tuff, Lawrence Livermore National Laboratory, Livermore, CA, UCRL-ID-122899.

Itasca Consulting Group, Inc., 1993 FLAC User's Manual, vol. I-III (Minneapolis, MN).

Lee, K. H. (1995), Progress Report on Pre-Test Calculations for the Large Block Test, Lawrence Livermore National Laboratory, Livermore, CA, UCRL-ID-118669.

Price, R., et al. (1993), "Laboratory Determination of the Mechanical Properties of Fractures," YMP Study Plan 8.3.1.15.1.4 RO, U.S. Department of Energy, Washington, DC.

Roberts, J. (1996), Report on Laboratory Tests of Drying and Re-Wetting of Intact Rocks, Lawrence Livermore National Laboratory, Livermore, CA, UCRL-ID-121513.

U.S. Department of Energy (1991), Reference Information Base, Yucca Mountain Project Characterization Office, YMP/CC-0002, Version 4, Rev. 3 (NNA.911118.0131).

Zimmerman et al. (1986), Final Report: G-Tunnel Heated Block Experiment, Sandia National Laboratories, Albuquerque, NM, -2620 


\section{Appendix A FLAC Mechanical Model Input File}

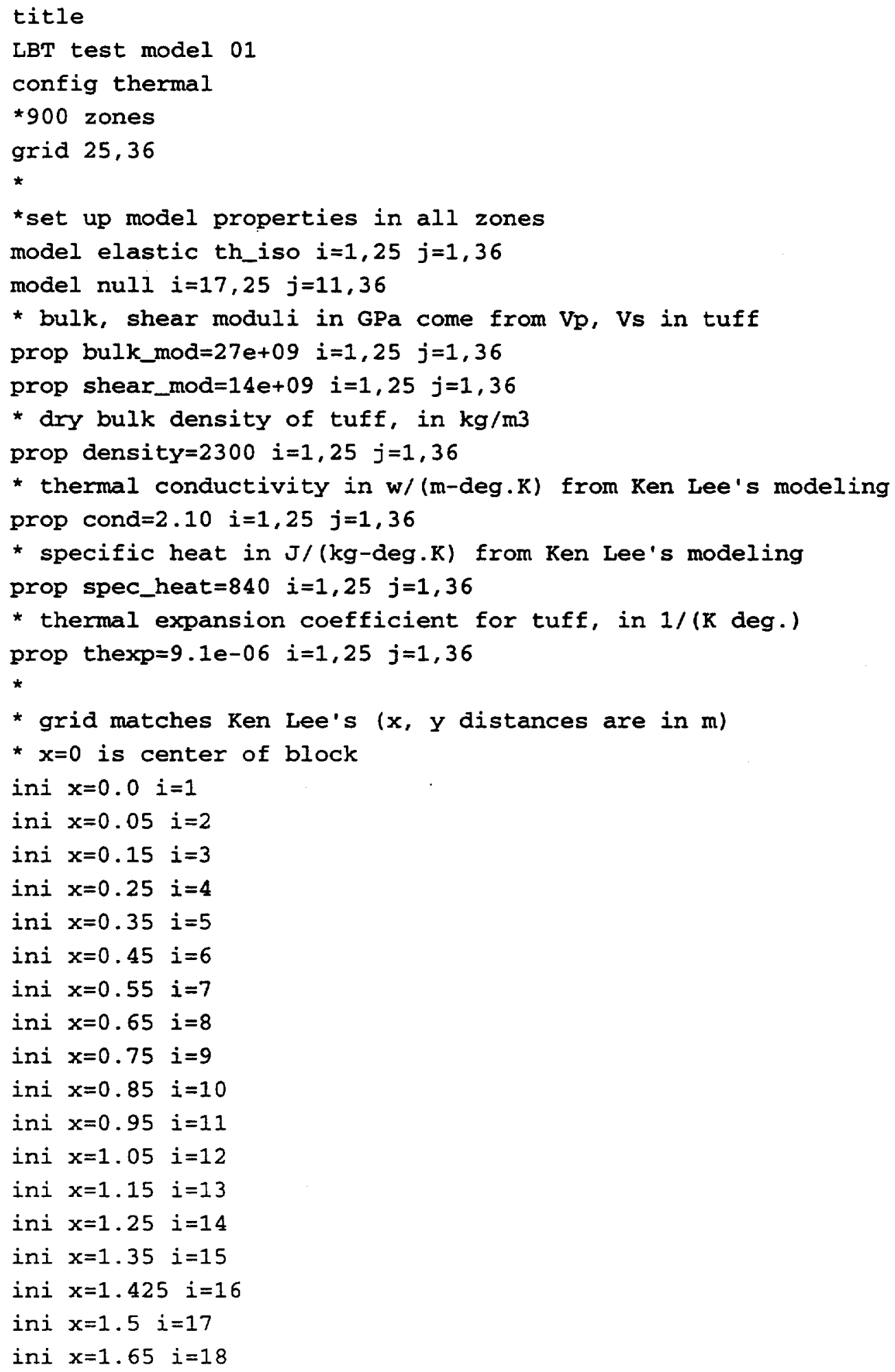


ini $x=1.90 \quad i=19$

ini $x=2.3 \quad i=20$

ini $x=3.0 \quad i=21$

ini $x=4.0 \quad i=22$

ini $x=6.0 \quad i=23$

ini $x=10.0 \quad i=24$

ini $x=18.0 \quad i=25$

ini $x=34.0 \quad i=26$

*

* ground surface is $y=0$; block is $y>0$; below block is $y<0$

ini $y=-40.5 j=1$

ini $y=-24.5 j=2$

ini $y=-12.5 j=3$

ini $y=-6.5 j=4$

ini $y=-3.5 j=5$

ini $y=-2.0 \quad j=6$

ini $y=-1.25 j=7$

ini $y=-0.75 j=8$

ini $y=-0.45 j=9$

ini $y=-0.2 j=10$

ini $y=0.0 \quad j=11$

ini $y=0.2 j=12$

in1 $y=0.4 \quad j=13$

ini $y=0.6 \quad j=14$

ini $y=0.8 \quad j=15$

ini $y=1.0 \quad j=16$

ini $y=1.2 \quad j=17$

ini $y=1.35 j=18$

ini $y=1.45 j=19$

ini $y=1.55 j=20$

ini $y=1.65 j=21$

ini $y=1.8 \quad j=22$

ini $y=1.95 j=23$

ini $y=2.15 j=24$

ini $y=2.35 j=25$

ini $y=2.55 j=26$

ini $y=2.75 j=27$

ini $y=2.95 j=28$

ini $y=3.15 j=29$

ini $y=3.35 j=30$

ini $y=3.55 j=31$

ini $y=3.75 j=32$

ini $y=3.95 j=33$

ini $y=4.15 j=34$

ini $y=4.35 j=35$

ini $y=4.45 j=36$ 
ini $y=4.50 \quad j=37$

*

* cut heater holes

* comment out these lines since zones are too big

* for heater holes, with the current grid

* gen arc $0.0,1.50 .1 .47180$.

* gen circle $0.6,1.5 \quad 0.03$

* gen circle $1.2,1.5 \quad 0.03$

*

* mechanical boundary, initial conditions

set grav $=9.8$

ini $s x x=0$. syy=0. $s z z=0$.

* fix plane of symmetry, bottom of model, far edge of model

fix $x i=1$

fix $x$ y $j=1$

fix $x$ y $i=26 j=1,11$

* apply compressive stresses to top, side of block; and to ground surface

* (units are Pa; about 15psi for $0.1 \mathrm{MPa}$ )

apply syy $=-1.0 e+05 \quad i=1,17 j=37$

apply sxx=-1.0e+05 $i=17 j=11,37$

apply syy $=-1.0 e+05 i=17,26 j=11$ 


\section{Appendix B FLAC Thermal Model Input File}

* thermal boundary, initial conditions

*

* model boundaries automatically adiabatic in FLAC

*

* side of block and ground surface are adiabatic since null zone

* doesn't conduct heat

*

* (units are deg. K)

ini temp=293

* make bottom of model, far edge of model, ground surface isothermal

fix temperature $=293 j=1$

fix temperature $=293 i=26, j=1,11$

fix temperature $=293 \quad i=17,26 \quad j=11$

*

*

* heaters

*

* each hole is about 2 inches in diameter and contains a 300 watt heater

* (only model half of block, or 2.5 heaters)

*

* each heater is cylinder with volume $\mathrm{pi} *(0.025 \mathrm{~m})(0.025 \mathrm{~m})(2.7 \mathrm{~m})=$

* about $0.0053 \mathrm{~m} 3$

$\star$

* a heater is a source having $300 \mathrm{w} / 0.0053 \mathrm{~m} 3=$

* about $5.7 \mathrm{e}+04 \mathrm{w} / \mathrm{m}^{3}$

*

* the heater holes are smaller than a grid zone, but

* entire zone gets used as source, and zone has

* area of $10 \mathrm{~cm} \times 10 \mathrm{~cm}=0.01 \mathrm{~m} 2$ while heater holes

* have cross-sectional area $0.0020 \mathrm{~m} 2$

$\star$

* to get the right size source, use $5.7 \mathrm{e}+04 \mathrm{w} / \mathrm{m} 3 * 0.0020 \mathrm{~m} 2 / 0.01 \mathrm{~m} 2=$

* about $1.1 \mathrm{e}+04 \mathrm{w} / \mathrm{m} 3$

interior source $=1.1 e+04 i=1 \quad j=19$

interior source $=1.1 e+04 \quad i=7 \quad j=19$

interior source $=1.1 e+04 \quad i=13 \quad j=1$ 


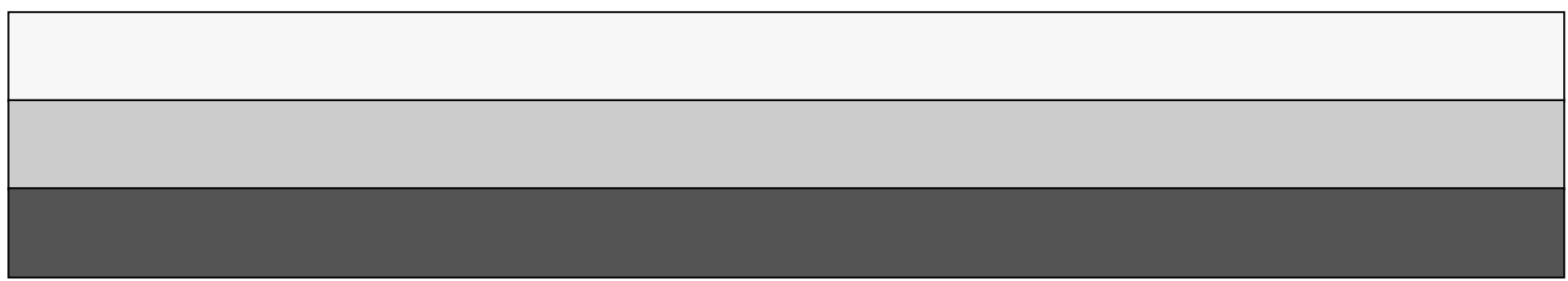

